Cahiers de recherches médiévales

\title{
Adenet le Roi tel qu'en ses prologues
}

Silvère Menegaldo

\section{(2) OpenEdition}

Journals

Édition électronique

URL : https://journals.openedition.org/crm/11717

DOI : $10.4000 / \mathrm{crm} .11717$

ISSN : 1955-2424

Éditeur

Honoré Champion

\section{Édition imprimée}

Date de publication : 20 novembre 2009

Pagination : 309-328

ISSN : 1272-9752

\section{Référence électronique}

Silvère Menegaldo, «Adenet le Roi tel qu'en ses prologues », Cahiers de recherches médiévales [En ligne], 18 | 2009, mis en ligne le 15 décembre 2012, consulté le 15 décembre 2022. URL : http:// journals.openedition.org/crm/11717 ; DOI : https://doi.org/10.4000/crm.11717 
Regard sur une aeuvre : Adenet le Roi sous la direction de Silvère Menegaldo 


\section{RM}

\section{Adenet le Roi tel qu'en ses prologues}

Abstract: By a close examination of all the prologues (and also epilogues) of the four known works of Adenet le Roi (Buevon de Conmarchis, the Enfances Ogier, Berte as grans piés and Cleomadés), this study would like to show how the poet, while keeping a generic distinction between chanson de geste at one side and romance at the other side, conceives his work as a whole and offers a portrait of himself as a minstrel escrivain, mastering an art of words and writing rather than of orality and music.

Résumé: En examinant de façon attentive l'ensemble des prologues (mais aussi des épilogues) des quatre compositions connues d'Adenet le Roi (Buevon de Conmarchis, les Enfances Ogier, Berte as grans piés et Cleomadés), cette étude voudrait montrer comment le poète, tout en maintenant une distinction générique entre chanson de geste d'un côté et roman de l'autre, conçoit son xuvre comme un tout et propose un portrait de lui-même comme ménestrel escrivain, exerçant un art des mots et de l'écriture plutôt que de l'oralité et de la musique.

Grâces soient rendues à la philologie belge, en l'occurrence à la magistrale édition publiée entre 1951 et 1971 par Albert Henry ${ }^{1}$, Adenet le Roi fait aujourd'hui partie des rares auteurs du $\mathrm{XIII}^{\mathrm{e}}$ siècle dont on puisse prétendre avoir une connaissance un peu plus qu'approximative ${ }^{2}$. Menestrel, et même roi- signe, certainement, d'une position point trop subalterne - parmi eux, comme il se qualifie lui-même à plusieurs reprises dans ses textes et comme il est désigné dans divers documents d'archives, Adenet, d'abord protégé du duc Henri III de Brabant (mort en 1261), passe probablement le reste de son existence au service de Gui de Dampierre, comte de Flandre, de 1270 au plus tard jusqu'à la fin du XIII ${ }^{\mathrm{e}}$ siècle, sans qu'il soit possible d'être plus précis - le dernier document mentionnant le poète date de 1297 , et Gui de Dampierre meurt en 1304, mais peut-être le ménestrel l'a-t-il précédé3.

D'Adenet le Roi on connaît aujourd'hui quatre compositions, dont il donne lui-même la liste au début de la dernière d'entre elles, le roman de Cleomadés :

Je qui fis d'Ogier le Danois

Et de Bertain qui fu ou bois

${ }^{1}$ A. Henry, Les CEuvres d'Adenet le Roi, t. 1, Biographie d'Adenet. La tradition manuscrite, t. 2, Buevon de Conmarchis, t. 3, Les Enfances Ogier, t. 4, Berte aus grans piés, t. 5, Cleomadés, Bruges puis Bruxelles, 1951-1971 (réimp. Genève, Slatkine, 1996).

${ }^{2}$ Suffisamment en tout cas pour qu'une présentation spécifique de l'auteur, dans ce «Regard sur une œuvre » consacré à Adenet le Roi, ne nous ait pas semblé nécessaire ; on trouvera en revanche, sur le site arlima.net, une bibliographie mise à jour par nos soins.

${ }^{3}$ Pour un exposé biographique détaillé, voir le tome un des Euvres d'Adenet le Roi, p. 11-81. On trouvera les mêmes données présentées de façon plus synthétique dans le chapitre « Adenet et son œuvre » de Berte as grans piés, éd. A. Henry, Genève, Droz, 1982, p. 19-28.

Cahiers de Recherches Médiévales, 18, 2009 
Et de Buevon de Conmarchis

Ai un autre livre rempris,

Mout merveilleus et mout divers. (v. 5-9)

Les trois premiers de ces textes, comme le nom de leur héros l'indique assez, ainsi que leur forme (la laisse de décasyllabes ou d'alexandrins), relèvent de la chanson de geste, tandis que le dernier, Cleomadés, est un roman d'aventures composé en couplets d'octosyllabes. Des éléments de critique interne permettent de situer leur composition entre 1270 et 1285 environ, ce qui fait d'Adenet le Roi un auteur plutôt prolixe, étant donné l'ampleur des textes considérés, de 3486 vers pour Berte as grans piés et 3947 vers pour Buevon de Conmarchis à 8229 vers pour les Enfances Ogier et rien moins que 18698 vers pour Cleomadés. Quant à la chronologie de ces textes, si l'ordre de succession proposé par Adenet lui-même n'est pas à exclure, A. Henry tend plutôt, notamment pour des raisons stylistiques, à placer en tête Buevon, suivi d'Ogier, de Berte et enfin de Cleomadés.

À l'exception de Buevon, conservé (amputé de sa fin) dans un seul manuscrit, on peut considérer que l'œuvre d'Adenet le Roi a connu une diffusion relativement homogène, puisqu'on conserve pour chacune de ses trois autres compositions environ une dizaine de copies complètes. On notera cependant que ces textes ont surtout circulé de façon indépendante, et non comme un ensemble attaché à un même auteur, puisque seul un manuscrit, le 3142 de la Bibliothèque de 1'Arsenal, contient toute l'œuvre d'Adenet le Roi, et encore est-ce en séparant Buevon (f. $179 \mathrm{r}^{\circ}-201 \mathrm{v}^{\circ}$ ) - qui décidément fait bande à part - de l'ensemble Cleomadés / Ogier / Berte (f. $\left.1 \mathrm{r}^{\circ}-140 \mathrm{v}^{\circ}\right)$. Même si c'est à une époque où les manuscrits centrés sur le corpus d'un ou plusieurs auteurs sont encore rares, il semble donc que considérer l'œuvre du ménestrel comme un tout ne soit pas allé de soi, en dépit même des intentions affichées en ce sens par l'auteur dans le prologue du Cleomadés; une attitude qui s'est d'ailleurs en partie perpétuée jusqu'à aujourd'hui, la critique moderne continuant de réserver à la production d'Adenet un traitement très inégal, où Berte et Cleomadés se trouvent nettement privilégiés. Il n'est guère qu'A. Henry, en somme, au terme de son travail éditorial au long cours, qui ait été en position de formuler quelques remarques s'autorisant d'un regard d'ensemble sur l'œuvre: outre divers traits d'écriture communs aux quatre textes, le savant belge a ainsi pu mettre en évidence une "personnalité $»^{4}$ littéraire en même temps qu'une évolution dans la carrière du poète, Adenet le Roi devenant au fil du temps, toujours selon A. Henry, de plus en plus romancier - évolution qui paraît aller en quelque

\footnotetext{
${ }^{4}$ "Adenet écrivain est une personnalité assez séduisante, qui sait être courageuse, malgré la situation sociale de l'homme. Ses enthousiasmes ont leurs racines dans sa sensibilité et dans son intelligence. La musique, les livres, Paris, l'idée France l'inspirent. Ce qu'il peint le mieux, ce sont les émotions intellectuelles, la contemplation sereine du spectacle de la nature, l'émoi des personnages qui se retrouvent après une longue absence, les troubles du cœur féminin, les joies naïves, la délicatesse des âmes solitaires. Homme de goût, il a été aussi, en tant qu'écrivain, un excellent connaisseur de sa langue » (introduction à l'éd. de Berte as grans piés, p. 27-28). On notera que, plus condensé, le jugement global porté sur Adenet par A. Henry en 1982 est aussi plus favorable que celui qu'il développait en 1951, p. 59-64 du tome 1 des Euvres d'Adenet le Roi.
} 
sorte de soi, Cleomadés étant la dernière œuvre composée par le ménestrel, et de fait la plus romanesque.

Cependant il est peut-être un trait de la personnalité littéraire d'Adenet le Roi qu'A. Henry n'a pas assez souligné, et qui pourtant constitue aussi un trait d'union entre Buevon, Ogier, Berte et Cleomadés : c'est la représentation qu'Adenet donne de la genèse de ses textes, de son travail de poète et de lui-même en tant qu'auteur dans ses différents prologues (et épilogues), qui - sans pour autant bouleverser la tradition épique ou romanesque dont ils sont tributaires - se distinguent à la fois par l'ampleur de leur développement et les nombreuses correspondances qui les lient ${ }^{5}$. L'intérêt que peut présenter, à différentes époques et pour différents genres, l'étude des «seuils» dans la littérature médiévale n'étant plus à démontrer ${ }^{6}$, c'est la voie que nous nous proposons de suivre à présent, pour tâcher de mieux cerner le menestrel Adenet et son œuvre.

\section{Une conscience générique bien marquée}

Un regard même superficiel suffit à repérer entre les quatre prologues d'Adenet le Roi assez de points de contact, comme de divergences, pour permettre de les regrouper d'emblée en deux ensembles : les trois prologues épiques (Buevon, Ogier, Berte) et le prologue romanesque (Cleomadés). Même s'il est vrai que dès le $\mathrm{XIII}^{\mathrm{e}}$ siècle les textes liminaires épiques et romanesques partagent nombre de topiques ${ }^{7}$, et qu'à la même époque les différences entre les deux genres narratifs

\footnotetext{
${ }^{5}$ Quoique ces prologues, à ma connaissance, n'aient jamais donné lieu à une étude d'ensemble, certains d'entre eux ont déjà bénéficié de forts bons commentaires, dont nous ne craindrons pas de nous inspirer, en particulier: Y. Foehr-Janssens, La Veuve en majesté, Genève, Droz, 2000, p. 173-179 (prologue de Berte); A. Berthelot, «Cleomadés de la conjointure au déploiement », Styles et valeurs. Pour une histoire de l'art littéraire au Moyen Âge, éd. D. Poirion, Paris, SEDES, 1990, p. 9-19 (prologue de Cleomadés).

${ }^{6}$ Parmi une vaste bibliographie sur le sujet, on renverra particulièrement, pour s'en tenir à la littérature française, aux deux recueils d'études suivants: Prologues et épilogues dans la littérature du Moyen Âge, éd. A. Petit, Bien dire et bien aprandre, 19, 2001 ; Seuils de l'œuvre dans le texte médiéval, éd. E. Baumgartner et L. Harf-Lancner, Paris, Presses de la Sorbonne Nouvelle, 2002, deux tomes. On a consulté également les deux articles bien connus de P. Gallais («Recherches sur la mentalité des romanciers français du Moyen Âge », Cahiers de civilisation médiévale, 7, 1964 et 13, 1970, p. 479-493 et 333-347) et de P.-Y. Badel («Rhétorique et polémique dans les prologues de romans au Moyen Âge », Littérature, 20, 1975, p. 81-94).

${ }^{7}$ Sur les prologues de chansons de geste spécifiquement, voir D. Boutet, La Chanson de geste, Paris, PUF, 1993, p. 13-33 ; J.-P. Martin, « Sur les prologues des chansons de geste: structures rhétoriques et fonctions discursives ", Le Moyen Âge, 93, 1987, p. 185-201; M. Bensi, "L'élaboration rhétorique du prologue dans les chansons de geste », VIII Congreso de la Société Rencesvals, Pampelune, Institucion Principe de Viana, 1981, p. 393-397; M. Gsteiger, "Note sur les préambules des chansons de geste», Cahiers de civilisation médiévale, 2, 1959, p. 213-220. Rappelons avec D. Boutet (op. cit., p. 20) que dans ces prologues épiques «les interférences avec le monde intellectuel du roman sont apparues très tôt »; voir aussi sur ce point précis E. Baumgartner, "Texte de prologue et statut du texte »,
} 
tendent à s'estomper, y compris chez notre auteur, il n'en reste pas moins que quelques éléments bien précis permettent de distinguer dans quel moule traditionnel Adenet entend se couler.

\title{
Les trois prologues épiques
}

Une fois que la mesure est prise de leur longueur, plus (33 vers dans Buevon de Conmarchis ${ }^{8} ; 56$ vers dans les Enfances Ogier, complétés par un épilogue de 29 vers) ou moins (22 vers dans Berte as grans piés) remarquable, on ne peut manquer de constater que les trois prologues épiques d'Adenet, en dépit de certaines différences, sont tous conçus sur un patron similaire, où plusieurs topiques occasionnent les mêmes développements et se retrouvent associés de façon récurrente : la reverdie; la mention d'une source livresque consultée à l'abbaye de Saint-Denis ; la prétention de relater la vraie estoire, qui ne sera pas faussee comme celle des mauvais jongleurs, mais bien rimee. Nous allons donc examiner la mise en œuvre de ces topiques, en citant à chaque fois en tête de chaque série d'exemples le prologue de Berte, où l'enchaînement de ces différents éléments est le plus lisible, puisque ce sont les seuls qu'Adenet utilise dans le plus court de ses trois prologues.

Commençons donc par la reverdie, sur laquelle s'ouvrent deux des trois textes liminaires :

\author{
A l'issue d'avrill, un tans douç et joli, \\ Que herbeletes pongnent et pre sont raverdi \\ Et arbrissel desirent qu'il fussent parflori... (Berte, v. 1-3) \\ Ce fu ou tans d'esté, si comme ou mois de mai, \\ $\mathrm{K}$ 'en maint lieu resplendissent cler dou soleil li rai \\ Et que arbre florissent et pre sont vert et gai... (Buevon, v. 1-3) \\ Droit enz ou tans k'yver couvient cesser, \\ Que arbrissel prennent a boutonner \\ Et herbeletes commencent a lever... (Ogier, v. 36-38)
}

Comme l'a bien noté Y. Foehr-Janssens dans son commentaire du prologue de Berte, par cette «banale ouverture printanière», Adenet le Roi s'inscrit dans une tradition, bien attestée dans la chanson de geste (par exemple dans Le Charroi de Nîmes ou La Prise d'Orange) et ailleurs ${ }^{9}$, qui fait coïncider la reverdie avec le début $\mathrm{du}$ récit. Le poète introduit tout de même un décalage, dans la mesure où le renouveau printanier marque ici non pas le début du récit à proprement parler, mais

Essor et fortune de la chanson de geste dans l'Europe et l'Orient latin. Actes du $9^{\text {ème }}$ Congrès international de la Société Rencesvals, Modène, Mucchi, 1984, p. 465-473.

${ }^{8}$ On ne tiendra pas compte ici de la laisse 2 de Buevon, qui prolonge plus ou moins le prologue, sans rien y ajouter de nouveau, tout en entamant le récit.

${ }^{9}$ Voir sur ce point M. Le Person, «L'insertion de la reverdie comme ouverture ou relance narratives dans quelques romans des $\mathrm{XII}^{\mathrm{e}}$ et XIII" siècles », Les Genres insérés dans le roman, éd. C. Lachet, Université Jean Moulin-Lyon III, 1993, p. 17-33. 
celui de la narration, ou de l'histoire du récit ${ }^{10}$, proposant ainsi une sorte de déclinaison lyrique du topique qui met Adenet dans la position du trouvère de la chanson d'amour. Cependant, comme le constate encore Y. Foehr-Janssens, «cet agencement n'est pas totalement inédit $\rangle^{11}$, puisqu'on le trouve aussi dans le prologue de Girart de Vienne, par exemple, ou encore dans celui de Partonopeu de Blois. Dans un premier temps, Adenet ne semble donc pas s'inscrire dans un genre particulier, le topique de la reverdie n'étant a priori pas plus épique que romanesque; on notera néanmoins que le poète n'y a pas recours dans le prologue de Cleomadés.

Ce n'est donc pas le début du récit qu'annonce la reverdie, mais l'histoire de sa genèse, qui dans les trois prologues suit exactement le même déroulement :

Tout droit en cel termine que je ici vous di,

A Paris la cité estoie un venredi ;

Pour ce qu'il ert devenres, en mon cuer m'assenti

K'a Saint Denis iroie por priier Dieu merci.

A un moine courtois, c'on nonmoit Savari,

M'acointai telement, Damedieu en graci,

Que le livre as estoires me moustra et g'i vi

L'estoire de Bertain et de Pepin aussi. (Berte, v. 4-11)

Tout droit en cel termine dont je parlé vous ai,

A Saint Denis en France la droite voie alai.

A un moine courtois sagement m'acointai,

Dans Nicholas ot non, car je li demandai ;

D'estoires ancïennes enquis et encerchai.

De la geste Aymeri quis tant et reverchai

Que je la vraie estoire avoec moi enportai,

Hors d'un moult tres biau livre la matere en puisai. (Buevon, v. 11-18)

Ala Adans, plus ne volt demourer,

A Saint Denis en France demander

Coument porra de ceste estoire ouvrer.

$[\ldots]$

Uns courtois moines, cui Dieus puisse honnorer,

Dant Nicolas de Rains l'oÿ nommer,

Li fist l'estoire de chief en chief moustrer. (Ogier, v. 39-41 et 46-48)

Sur ce point non plus on ne peut pas dire qu'Adenet fasse preuve de beaucoup d'originalité, l'allégation d'une source livresque empruntée à l'abbaye de SaintDenis n'ayant rien d'exceptionnel dans le contexte épique. On notera cependant que le poète ne se contente pas, comme dans d'autres chansons de geste, d'indiquer

\footnotetext{
${ }^{10}$ Preuve qu'il s'agit de deux usages différents du même topique, sa répétition à peu de distance dans Buevon, d'abord en tête du prologue, puis au commencement du récit proprement dit, au début de la laisse 3 (v. 53-55).

${ }^{11}$ Y. Foehr-Janssens, op. cit., p. 173 et 174.
} 
comme en passant la source de son récit, en un ou deux vers («L'estoire en est el role a Saint Denis ; / Mout a lonc tans qu'ele est mise en obli ») $)^{12}$. Au contraire il attache à cette mention un intérêt particulier, la développant en « une sorte de petit récit», «un petit roman personnel $»^{13}$ où il s'implique directement et personnellement; c'est façon non seulement de mettre en vedette la personne de l'auteur, mais aussi de bien insister sur les origines du récit, et partant sur son appartenance générique. En effet l'abbaye de Saint-Denis est de longtemps identifiée, à l'époque où écrit Adenet, comme le lieu où se consigne l'histoire de France, en latin puis à partir du XIII ${ }^{\mathrm{e}}$ siècle en français (notons, plus près d'Adenet, que le moine Primat offre son Roman des rois à Philippe III en 1274); or la matière de France est par excellence épique, et que je sache aucun prologue de roman n'a jamais eu l'idée d'alléguer une source dyonisienne. Mettre ainsi en évidence, dans les trois prologues, l'abbaye de Saint-Denis, c'est dire très clairement, quoi qu'il en soit par ailleurs de leur contenu, que Buevon, Ogier et Berte sont indubitablement des chansons de geste.

Et si Adenet se rend à Saint-Denis, c'est que là seulement il est assuré de trouver la vraie estoire:

Aprentiç jougleour et escrivain mari,

Qui l'ont de lieus en lieus ça et la conqueilli,

Ont l'estoire faussee, onques mais ne vi si.

Ilueques demorai de lors jusqu'au mardi

Tant que la vraie estoire enportai avoec mi.

$[\ldots]$

L'estoire iert si rimee, par foi le vous plevi,

Que li mesentendant en seront abaubi

Et li bien entendant en seront esjoy. (Berte, v. 13-17 et 20-22)

Pour ce qu'est mal rimee, la rime amenderai

Si a droit que l'estoire de riens ne fausserai,

Mençonge ne oiseuse ja n'i ajousterai

Mais parmi la matere droite voie en irai.

Je ne vous dirai mie dou songe Erminolai

$\mathrm{Ne}$ conment Crucados ala au virelai

Quant il trouva les fees en la forest dou glai,

Ains dirai vraie estoire dont ja ne mentirai. (Buevon, v. 21-28)

Cil jougleour qui ne sorent rimer

$\mathrm{Ne}$ firent force fors que dou tans passer,

L'estoire firent en plusours lieus fausser.

[...]

Ala Adans, plus ne volt demourer,

A Saint Denis en France demander

Coument porra de ceste estoire ouvrer,

${ }^{12}$ Prologue du Moniage Guillaume, cité par M. Gsteiger, art. cit., p. 219.

${ }^{13}$ Ibid. et Y. Foehr-Janssens, op. cit., p. 178. 
Par quoi le puist seur verité fonder;

Car n'i vorra nule riens ajouster,

Fors que le voir, et mençonges oster ;

La ou seront les vorra fors sarcler. (Ogier, v. 13-15 et 39-45)

En fait, il s'agit plutôt ici de trois topiques différents (vérité de l'estoire, critique des versions antérieures, mise en avant de la qualité de facture de la chanson), mais qui se trouvent très étroitement associés dans les prologues de Buevon et de Berte, et c'est pourquoi nous les abordons comme un ensemble. Là encore la prétention de relater une histoire véridique, une histoire où ne se trouvent que verité et rien fors que le voir, n'a rien de très remarquable et se trouve affichée dans de nombreux prologues épiques, parfois avec une insistance parfaitement comparable à celle dont Adenet fait lui-même preuve (ainsi dans des formules redondantes comme : "Tote est de voire estoire sans point de fausseté $\gg)^{14}$. Mais en quoi cette estoire est-elle tellement plus vraie que les autres? Qu'elle provienne de l'abbaye de Saint-Denis est évidemment une garantie de son authenticité, mais n'explique pas tout. En effet, le poète se doit aussi de préciser que ses prédécesseurs, ces « jougleour qui ne sorent rimer », ces «aprentiç jougleour» et ces « escrivain mari» (on reviendra sur ce rapprochement a priori curieux) sont responsables d'avoir faussé l'histoire, ce qu'il faut visiblement entendre dans un double sens : à la fois d'avoir dit des choses fausses, des «mençonges », et de les avoir mal dites, sans art, en une chanson «mal rimee ». En se distinguant des mauvais jongleurs qui n'ont pas été capables de respecter cette équivalence entre bien dire et dire le vrai ${ }^{15}$, Adenet fait donc aussi la promotion de ses propres talents de poète et de son aptitude à composer une chanson "gracieuse a dire et a chanter » (Ogier, v. 52), en somme une bone chanson, comme tant d'autres prologues épiques en ont la prétention ${ }^{16}$.

Il faut tout de même préciser, avant d'achever ce développement sur les prologues épiques, que celui des Enfances Ogier présente quelques particularités qui le distinguent des deux autres. C'est en effet le seul à comporter le nom d'Adenet, désigné comme «le Roi Adam», et le seul aussi qui fasse mention d'un commanditaire pour qui le texte a été composé :

Li Rois Adans ne veut plus endurer

Que li estoire d'Ogier le vassal ber

Soit corrompue ; pour ce i veut penser

Tant qu'il le puist a son droit ramener,

K'au Roi Adam le plaist a commander

Celui que il ne doit pas refuser

Que ses commans ne face sanz veer :

C'est li quens Guis de Flandres seur la mer.

\footnotetext{
${ }^{14}$ Dans Bueve d'Aigremont et Renaut de Montauban (cité par M. Gsteiger, art. cit., p. 218).

${ }^{15}$ Au-delà de la critique traditionnelle adressée aux mauvais jongleurs, il n'est pas impossible, dans le prologue de Buevon (v. 25-28), qu'Adenet vise plus spécifiquement certaines chansons de geste plus ou moins contemporaines, comme Huon de Bordeaux par exemple, où l'élément merveilleux occupe une place particulièrement importante.

${ }^{16}$ M. Gsteiger, art. cit., p. 215-216.
} 


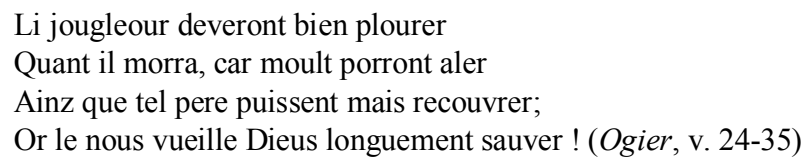

À n'en pas douter, on trouverait plus volontiers de tels éléments dans le prologue d'un roman que dans celui d'une chanson de geste; en particulier la mention d'un nom de commanditaire (Gui de Dampierre, patron d'Adenet le Roi pendant plusieurs décennies), qui va évidemment de pair avec son éloge, est plutôt exceptionnelle dans un tel cadre; on notera cependant qu'Adenet préserve en quelque sorte sa liberté de poète, en ne faisant état du comman de Gui de Flandre qu'après avoir dit son plaisir à raconter cette histoire («Pour ce me plaist estoire a deviser...», v. 6), qu'il ne pouvait plus «endurer» de voir «corrompue». En outre, au prologue d'Ogier répond un assez long épilogue (v. 8201-8229), ce qu'on ne rencontre guère non plus dans la chanson de geste, comportant qui plus est un envoi final de quatre vers à la reine de France Marie de Brabant (seconde épouse de Philippe III le Hardi), destinataire très inhabituel pour un texte épique.

Dans le cas spécifique d'Ogier, il semble donc que l'on puisse relever certaines interférences entre paratexte épique et romanesque, ce qui pourrait peutêtre expliquer la longueur du prologue (56 vers), en même temps que sa construction un peu déroutante. En revanche les textes liminaires de Buevon et de Berte, qui ne comportent aucune mention similaire, ne sont, nous semble-t-il, ni particulièrement originaux, ni particulièrement influencés par le $\operatorname{roman}^{17}$, tous les topiques qu'ils mettent en œuvre se trouvant aussi bien dans d'autres chansons de geste, quoiqu'en général sous une forme moins développée. Bien plus, en prenant soin de mettre en évidence la source dyonisienne de ses compositions, Adenet assure à chacune d'entre elles, y compris Ogier, une nette appartenance au genre de l'épopée - ce qui ne veut évidemment pas dire que la réalisation narrative corresponde forcément à un tel affichage générique ${ }^{18}$. Enfin les trois prologues se rejoignent dans la place

\footnotetext{
${ }^{17}$ Contrairement à ce que dit G. Peron, art. cit., p. 396.

${ }^{18} \mathrm{Si}$ du moins l'on attend d'une chanson de geste de la fin du XIII ${ }^{\mathrm{e}}$ siècle qu'elle montre les mêmes caractéristiques qu'une chanson du XII' siècle... Sur cette question du caractère plus ou moins épique ou romanesque des chansons d'Adenet et de l'éventuel décalage entre affichage générique et réalisation textuelle, qui est encore discutée, voir notamment, à propos des Enfances Ogier, E. Hoyer-Poulain («Tradition / Trahison? Scènes de bataille dans les Enfances Ogier d'Adenet le Roi », Plaist vos oür bone cançon vallant? Mélanges François Suard, éd. D. Boutet, M.-M. Castellani, F. Ferrand et A. Petit, Université Charles-de-GaulleLille III, 1999, tome un, p. 435-444) et V. Méot-Bourquin («Les Enfances Ogier ou la chanson de geste entre tradition épique et conception courtoise ", L'Épique : fins et confins, éd. P. Frantz, Presses universitaires Franc-Comtoises, 2000, p. 127-153); et à propos de Berte as grans piés, Y. Foehr-Janssens ( «Une reine au désert: désolation et majesté dans Berte as grans piés d'Adenet le Roi », L'Épopée romane au Moyen Âge et aux temps modernes. Actes $d u X I V^{e}$ Congrès international Rencesvals, éd. S. Luongo, Naples, Fridericiana Editrice Universitaria, 2001, p. 229-245), ou tout simplement les deux articles qui suivent le nôtre dans le présent numéro des Cahiers de Recherches Médiévales.
} 
importante qu'ils font à l'auteur Adenet, mais c'est là une particularité qui ne les concerne pas seuls, puisqu'on la retrouve aussi dans Cleomadés.

\section{Le prologue romanesque}

Plus long encore que les trois prologues épiques (96 vers), celui de Cleomadés s'en distingue en outre par le recours des topiques spécifiques, parmi lesquels au moins deux (la liste d'œuvres et la commande féminine) paraissent fournir d'emblée des indications claires quant au genre auquel appartient la dernière œuvre d'Adenet.

Après une invocation initiale à Dieu, en effet, le prologue s'ouvre sur une liste d'œuvres composées par Adenet («Je qui fis d'Ogier le Danois / Et de Bertain qui fu ou bois...»), que nous avons déjà citée en introduction de cette étude. Quoiqu'une telle pratique ne soit pas tout à fait exclusive du roman (on la rencontre notamment dans le fabliau des Deus chevaus de Jean Bodel), elle est en tout cas suffisamment rare pour qu'on ne puisse manquer de penser - parallélismes dans l'expression aidant - à la liste bien connue que l'on trouve dans le prologue du Cligès de Chrétien de Troyes («Cil qui fist d'Erec et d'Enide / Et les conmandemenz d'Ovide...») ${ }^{19}$, ce qui, sans forcément placer Cleomadés sous le patronage du plus célèbre des romanciers médiévaux, situe néanmoins le texte dans l'orbe romanesque plutôt qu'épique.

Un second élément, plus déterminant, vient rapidement confirmer ce premier signe d'ancrage générique; si Adenet a «un autre livre rempris » (v. 8), c'est, poursuit-il, à la demande de «deus dames», qu'il préfère laisser temporairement dans l'anonymat, remettant la révélation de leur nom à la « fin de ce livre » (v. 35), programme qui sera en effet respecté dans l'épilogue sous forme d'acrostiche :

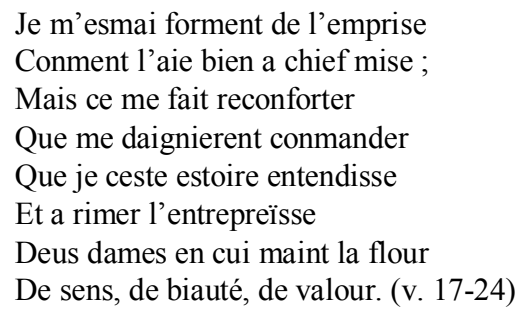

Que Cleomadés ait pour origine la commande de "deus dames » est un trait qui permet de signaler clairement son appartenance au genre romanesque. Il est vrai, comme on vient de le voir, que l'épilogue des Enfances Ogier se charge de les « envoiier» à Marie de Brabant, mais il s'agit d'un envoi, et non d'une commande ; il est possible aussi, comme l'a suggéré notamment R. Colliot, que Berte ait été destinée à la même personne ${ }^{20}$, mais rien dans le texte ne le dit explicitement. On sait

\footnotetext{
${ }^{19}$ Signalons que dans son étude consacrée au prologue de roman, P.-Y. Badel ne relève que deux textes où sont évoquées des «œuvres passées » (art. cit., p. 85), précisément Cligès et Cleomadés.

${ }^{20}$ R. Colliot, Adenet le Roi, «Berte aus grans piés ». Étude littéraire générale, Paris, Picard, 1970, tome un, p. 24-27.
} 
en revanche que de nombreux romans, dès le $\mathrm{XII}^{\mathrm{e}}$ siècle, allèguent dans leur paratexte une origine féminine, qu'il s'agisse d'un dédicataire nommément désigné, comme c'est ici le cas, ou bien d'un amour, réel ou imaginaire, censé inspirer l'écriture ${ }^{21}$. En faisant état de cette commande, avec en outre une insistance particulière $\mathrm{e}^{22}$, Adenet s'inscrit donc clairement dans une tradition associant le genre romanesque aux représentants féminins de la noblesse, à la fois origine et destination de l'ouvrage.

De même la définition qu'Adenet propose de son livre, «mout merveilleus et mout divers» (v. 9), en dépit d'une certaine ambiguité, paraît bien confirmer également cet affichage générique :

Mout est l'estoire de grant pris

Et a ö̈r mout gracieuse ;

Tant est diverse et merveilleuse

Que je croi c'onques nus n'oÿ

Si diverse comme cesti. (v. 12-16)

[Fasse Dieu]

Que je puisse venir a chief

De recorder de chief en chief

La tres plus merveilleuse estoire

Qui onques fust mise en memoire !

Bien doit estre en autorité,

Pour ce qu'ele est de verité

Estraite, dou tans ancïen,

Des le tans Deoclesien. (v. 87-94)

On mesure ici la plasticité (toujours actuelle) du terme «estoire», qui vaut aussi bien pour la vraie estoire de la chanson de geste que pour la merveilleuse estoire romanesque ${ }^{23}$; néanmoins le jeu des qualificatifs, répétés à plusieurs reprises,

\footnotetext{
${ }^{21}$ Sur les liens entre les femmes (commanditaires, dédicataires, public etc.) et le roman, voir notamment R. L. Krueger, Women Readers and the Ideology of Gender in Old French Verse Romance, Cambridge University Press, 1993. En outre, sur la question plus particulière de la femme aimée comme inspiratrice du roman, nous nous permettons de renvoyer à notre étude, "Quand le narrateur est amoureux : prologues et épilogues 'lyriques' dans le roman de chevalerie en vers aux $\mathrm{XII}^{\mathrm{e}}$ et XIII ${ }^{\mathrm{e}}$ siècles ", dans Prologues et épilogues dans la littérature $d u$ Moyen Âge, p. 149-165 (précisons que dans ce titre l'expression «roman de chevalerie» n'est pas très heureuse ; «roman d'aventures » serait préférable).

${ }^{22}$ Adenet consacre pas moins de 73 vers, soit les trois quarts de son prologue, à évoquer la commande des « deus dames » et à faire leur éloge, cela en répétant pas moins de cinq fois le verbe conmander ou un terme de la même famille.

${ }^{23}$ Sur les emplois d'estoire comme terme technique littéraire, voir notamment P. Gallais, art. cit., p. 338-342 et P. Damian-Grint, «Estoire as word and genre : meaning and literary usage in the twelfth century ", Medium Aevum, 66, 1997, p. 189-206 - où l'auteur, quoique se limitant aux textes historiographiques, montre bien que «an estoire is always a 'true narrative' » (p. 197)... ou du moins qui prétend l'être.
} 
semble imposer une distinction claire entre le domaine du roman et celui de l'épopée, entre le merveilleus d'un côté et le voir de l'autre. Ce qui n'empêche pas quelques hésitations de subsister, ainsi quand Adenet - décidément « gracieux et ambigu», comme dirait M. Mancini ${ }^{24}$ - mentionne une estoire «a ö̈r mout gracïeuse » de même qu'Ogier est une chanson " gracïeuse a dire et a chanter », ou quand il dit de l'histoire de Cléomadès qu'elle est de verité estraite... Contradictions seulement apparentes ou bien réelles, et trahissant un certain embarras d'Adenet face à l'« emprise » qu'on lui a imposée ?

Enfin le fait que Cleomadés, à côté de son très long prologue, comporte un épilogue encore plus long (près de deux cents vers) classe aussi clairement ce texte dans la catégorie du roman plutôt que de la chanson de geste, où les épilogues sont en général fort brefs, voire absents. Adenet consacre cet ample développement d'abord à révéler en acrostiche le nom des « deus dames » (la reine de France Marie de Brabant et Blanche de Castille), comme il l'avait promis dans son prologue (v. 18541-18586), puis à un remarquable excursus autobiographique, où après avoir donné son nom il revient sur sa carrière et les différents patrons qu'il a connus :

\author{
Ce livre de Cleomadés \\ Rimai je, li Rois Adenés. \\ Menestreus au bon duc Henri \\ Fui, cil m'aleva et norri \\ Et me fist mon mestier aprendre. (v. 18587-18591)
}

Adenet évoque ainsi tour à tour Henri III de Brabant, auprès de qui il a appris son mestier, et dont il regrette la mort, en précisant qu'il a assisté en personne à ses funérailles («Je meïsmes aussi i fui», v. 18638); Gui de Dampierre, comte de Flandre, dont il dirait plus de bien «se a lui n'estoi[t]» (v. 18659), ce qui prouve bien qu'au moment de l'achèvement de Cleomadés, Adenet est toujours à son service; les deux fils d'Henri III de Brabant, Jean et Godefroy, qui « Maintes fois [l']ont gardé dou froit» (v. 18672); enfin le comte d'Artois Robert II, auquel il envoie son livre «pour oÿr / Conment il est fais et dités » (v. 18690-18691). Voilà en somme un retour sur soi qui pourrait suggérer une carrière allant sur sa fin, voire peut-être un adieu à la littérature ${ }^{25}$. Dans l'impossibilité cependant d'aller plus loin dans cette direction, sauf à constater que Cleomadés est bien la dernière œuvre connue d'Adenet, on s'en tiendra à un constat plus évident, la place considérable qu'occupe dans cet épilogue « li Rois Adenés».

\footnotetext{
${ }^{24}$ M. Mancini, «Adenet gracieux et ambigu. À propos de l'édition A. Henry du Cleomadés », Cahiers de civilisation médiévale, 17, 1974, p. 51-57.

${ }^{25}$ Qu'on songe par exemple à Froissart énumérant ses anciens mécènes dans Le Joli Buisson de Jeunesse, cette œuvre constituant justement une sorte d'adieu à la poésie (mais non à la littérature, il est vrai).
} 


\section{Une conscience d'auteur bien affirmée: Adenet le Roi, ménestrel escrivain}

Plus que les relatives libertés qu'ils prennent vis-à-vis de la tradition épique et romanesque - tout en prenant bien garde d'assurer un affichage générique suffisamment lisible -, plus que l'inflation scripturale dont ils constituent en quelque sorte l'annonce - les textes liminaires d'Adenet n'étant pas si développés finalement, eu égard à la longueur des œuvres qu'ils encadrent -, ce qui ne manque pas de frapper dans ces prologues, et constitue leur trait commun le plus évident, c'est la place considérable qu'ils accordent au poète, leur véritable sujet en somme.

A la notable exception des Enfances Ogier, qui adoptent le mode en quelque sorte plus traditionnel de présentation de l'auteur (à la troisième personne, bien différenciée du narrateur qui s'exprime à la première), tous les prologues d'Adenet se distinguent d'abord par le large usage qu'ils font du je, qui ne sert pas seulement à désigner celui qui dit le récit, mais celui qui l'a composé :

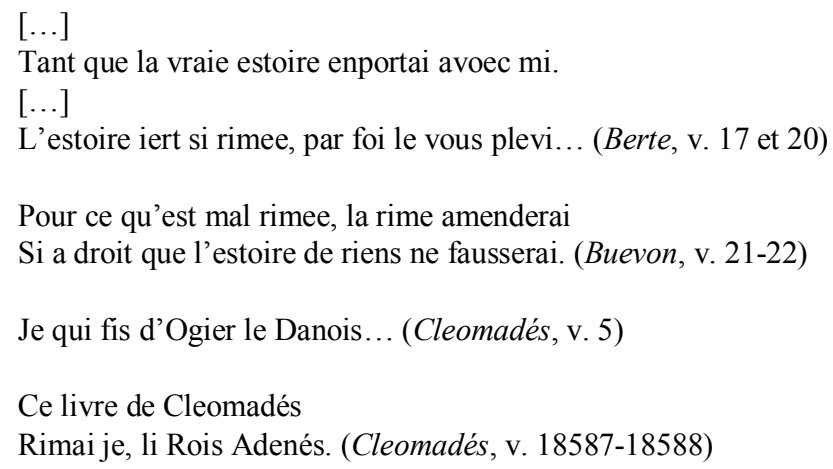

Plus que dans les prologues de Buevon et de Berte, où le nom de l'auteur n'est pas mentionné (mais connu grâce au prologue de Cleomadés), la mise en avant de l'auteur est particulièrement sensible dans Cleomadés, où je est d'abord donné pour celui qui a fait «d'Ogier le Danois / Et de Bertain qui fu ou bois...», et finalement qui a rimé «ce livre». L'auteur, grâce à cet usage de la première personne, n'est plus relégué à l'arrière-plan, ne s'efface plus pour passer le relais au narrateur, mais au contraire reste face à son public, auquel il s'adresse en son nom. C'est pourquoi on ne s'étonnera pas finalement de trouver le Cleomadés, alors qu'il s'agit de la dernière composition d'Adenet, en tête des œuvres rassemblées dans le manuscrit 3142 de la Bibliothèque de l'Arsenal.

En outre, loin de n'être qu'un nom, le poète acquiert chez Adenet une véritable épaisseur biographique, non seulement par la mention dans ses textes d'éléments réels que l'on peut vérifier par le document, comme les noms de ses commanditaires (ce qui n'est pas nouveau), mais surtout par un intéressant jeu de variation de focale, si l'on peut dire. En effet, à l'exceptionnel excursus autobiographique que propose l'épilogue du Cleomadés, qui permet d'embrasser l'ensemble de la carrière d'Adenet, depuis les années d'apprentissage de son mestier jusqu'au moment de l'achèvement du roman (vers 1285), s'opposent - de manière complémentaire - les trois micro-récits évoquant le séjour du ménestrel à Saint- 
Denis, dont on connaît même le moment (a l'issue d'avrill) et la durée précise (de vendredi à mardi) dans le prologue de Berte; l'illusion biographique - d'autant plus forte qu'Adenet a effectivement eu l'occasion de séjourner à Paris ${ }^{26}$ - est ici telle qu'un des éditeurs de Berte, U. T. Holmes, n'a pas craint d'user de ces éléments pour tenter de déterminer l'année de composition de la chanson ${ }^{27}$. Ainsi le texte parvient-il à offrir un regard d'ensemble sur l'existence du poète, tout en donnant l'impression de le voir vivre au jour le jour, courant les bibliothèques, prenant langue avec de courtois moines, parcourant les manuscrits - ce qui est façon, en même temps, de mettre en avant son entregent et sa culture.

Dans ses différents textes liminaires, Adenet propose également une définition du poète et de son travail, ce qui est moins inattendu, mais n'est pas sans soulever quelques questions quant au champ exact de ses compétences. Certes, on le sait par ses textes comme par des documents d'archives, Adenet est un menestrel : mais qu'est-ce à dire exactement ? En critiquant ses concurrents dans le prologue de Berte, le poète tient à se distinguer des "aprentiç jougleour» et des «escrivain mari» (v. 13), et de même dans le prologue d'Ogier des «jougleour qui ne sorent rimer» (v. 13); c'est dire, semble-t-il, qu'il ne récuse pas pour caractériser son propre statut les termes de jougleour ou d'escrivain, mais que bien évidemment il ne se tient pas lui-même pour un apprenti jongleur, un écrivain fourvoyé (sens probable de mari dans ce contexte) ou un rimeur incompétent. Ainsi Adenet, si l'on admet qu'il donne indirectement une définition de lui-même, ajoute au jougleour, autrement dit le poète qui chante (de geste), une composante scripturale, et se présente en somme comme un ménestrel escrivain.

Comment Adenet le Roi définit-il, ensuite, son travail de poète ? Il s'agit d'abord, comme le rappelle en particulier le prologue d'Ogier, d'un art de rimer:

L'estoire iert si rimee, par foi le vous plevi,

Que li mesentendant en seront abaubi

Et li bien entendant en seront esjoy. (Berte, v. 20-22)

Pour ce qu'est mal rimee, la rime amenderai

$\mathrm{Si}$ a droit que l'estoire de riens ne fausserai. (Buevon, v. 21-22)

Cil jougleour qui ne sorent rimer

$\mathrm{Ne}$ firent force fors que dou tans passer,

L'estoire firent en plusours lieus fausser,

D'amours et d'armes et d'onnour mesurer

Ne sorent pas les poins ne compasser,

\footnotetext{
${ }^{26}$ «Le comte de Flandre [Gui de Dampierre] était, en effet, d'humeur fort voyageuse. Les quelques comptes d'hôtel qui nous restent nous le montrent pérégrinant dans ses domaines et se rendant souvent à Paris ou ailleurs [...]. Adenet, son ménestrel, l'accompagna presque toujours dans ses déplacements : les documents l'attestent et les œuvres de l'écrivain montrent qu'il connaissait parfaitement la route de Paris et la grande cité elle-même » (A. Henry, Les Euvres d'Adenet le Roi, tome un, p. 43).

${ }^{27}$ Adenet le Roi's Berte aus grans piés, éd. U. T. Holmes, Chapel Hill, University of North Carolina, 1946, p. 9.
} 
Ne les paroles a leur droit enarmer

Qui apartienent a noblement diter ;

Car qui estoire veut par rime ordener,

Il doit son sens a mesure acorder

Et a raison, sanz point de descorder,

Ou il n'i puet ne ne doit assener. (Ogier, v. 13-23)

Le dernier texte cité, sorte d'art poétique en réduction, constitue un passage remarquable dans l'œuvre d'Adenet, et n'est pas d'ailleurs sans poser quelques problèmes de compréhension ${ }^{28}$. On en retiendra surtout une conception très intellectualisée du travail poétique, où il s'agit de mesurer, d'ordener, d'acorder sens a mesure, bien loin des simples formules publicitaires que l'on peut trouver dans les prologues épiques (du type «Seignours, oez chançon dont li ver sunt bien fait... » $)^{29}$. Les paroles et la rime constituent la texture du récit, que dans aucun des trois prologues épiques il n'est question de qualifier de chanson, mais seulement d'estoire - «gracieuse a dire et a chanter » (v. 52), il est vrai, dans le prologue d'Ogier. En somme on a le sentiment, même si cela reste implicite, que l'art de rimer d'Adenet est plus à concevoir comme un art de dire, voire d'écrire, que comme un art de chanter.

Par ailleurs l'art du poète ne se définit pas seulement comme une technique, aussi intellectualisée soit-elle, mais se pare également d'une portée morale, comme on le voit en particulier dans les prologues de Buevon et de Cleomadés (et d'Ogier dans une moindre mesure) :

Lors m'est pris volentés que tous jours maintenrai

- De cele volenté ja ne me partirai,

Se Dieu plaist et ses sains, tant com je viverai -,

Ce est que des preudomes volentiers parlerai :

Se d'aus sai aucun bien, je le recorderai ;

Se de nului sai mal, trestout quoi m'en tairai ;

Ainsi le doit on faire et ainsi le ferai. (Buevon, v. 4-10)

Bien doit chascuns son afaire arreer

A ce qu'il puist sa vie en bien user ;

Aumosnes est dou bien amonester

Et des preudoumes le bienfait recorder,

\footnotetext{
${ }^{28}$ Les v. 18-19 en particulier me paraissent poser problème, et notamment le verbe «enarmer», qui prend peut-être ici le sens technique d'«armorier» (une seule attestation dans le Tobler-Lommatzsch), quoique dans un emploi métaphorique; de son côté A. Henry (éd. cit., p. 336) propose de le traduire par «ajuster», ce qui correspond certes au contexte, mais guère au verbe lui-même. Adenet - dont l'intérêt pour l'héraldique a bien été mis en évidence dans plusieurs travaux récents de G. J. Brault (voir notamment « Adenet et l'héraldique médiévale », Olifant, 25, 2006, p. 141-149) - pourrait donc reprocher ici aux mauvais jongleurs de ne pas avoir su «armorier convenablement [autrement dit, "parer de la noblesse suffisante »] les propos qu'il convient de composer avec noblesse ».

${ }^{29}$ Prologue d'Orson de Beauvais, cité par M. Gsteiger, art. cit., p. 216.
} 


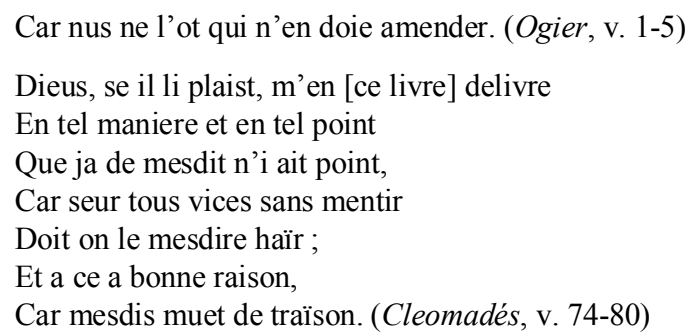

Recorder le bien et taire le mal, hä̈r le mesdire, voilà l'ambition morale - même s'il ne s'agit, selon la formule d'A. Henry, que de la «morale du ménestrel de cour », qui se caractérise par un "conformisme souriant $»^{30}-$ du poète Adenet, qui à l'équivalence déjà établie entre dire le vrai et bien dire, ajoute celle entre bien dire et dire le bien.

\section{Adenet en personnage, Adenet enluminé}

Ce portrait du ménestrel escrivain, tel qu'il se dessine dans les textes liminaires - personnel, autobiographique, technicien du vers et dispensateur de morale -, qui n'est pas sans rappeler quelques uns de ses contemporains (Baudouin et Jean de Condé, Watriquet de Couvin, par exemple), on en retrouve trace ailleurs que dans les prologues d'Adenet le Roi, ce qui permet d'en confirmer ou d'en préciser certains contours.

Ainsi Pinçonnet, le personnage de menestrel mis en scène dans Cleomadés, n'est pas sans rappeler Adenet lui-même, comme l'a constaté depuis longtemps la critique, en particulier dans le passage suivant - qui ne dit pas tant ce qu'est Pinçonnet que ce que doit être le droit menestrel:

Sachiez que Pinchonnés estoit

Mout liez, quand bien dire povoit.

C'est chose bien aferissans

Que menestreus soit bien disans

Et que il se gart de mesdire,

Car ramentevoir doit et dire

Li menestreus de bon afaire

Le bien et dou mal se doit taire,

Partout, en quel lieu que il soit,

Ou n'est pas menestreus a droit.

Droit menestreus se doit garder

De mesfaire et de mesparler ;

Ne doit mos issir de sa bouche

Qui a nul point de mesdit touche.

Tous jours doit estre apareilliez

Que par lui soit li biens nonciez

Par tous les lieus ou il venra.

Bien ait qui ainsi le fera. (v. 14073-14090)

${ }^{30}$ A. Henry, Les Euvres d'Adenet le Roi, tome un, p. 60-61. 
Se garder de mesdire, dire le bien et se taire dou mal, voilà qui rappelle de bien près et le prologue de Cleomadés et celui de Buevon. Pinçonnet, sorte de double fictif d'Adenet, et en même temps figure idéale de droit menestrel, se caractérise par la même ambition morale ; une ambition morale qui repose avant tout sur un rapport à la parole (on notera les répétitions de dire, mesdire, mesparler etc.), délimitant pour le poète un champ de compétences d'où la musique paraît absente. De fait, chez le personnage de Pinçonnet, les aptitudes musicales occupent une place bien secondaire (le roman le montre une seule fois seulement, au moment de son entrée en scène, en train de jouer « un pou de la kitaire », v. 10335), au regard de cet art de la parole qui le définit de façon quasi exclusive - trait que l'on retrouve, à la même époque, dans d'autres personnages de ménestrels, par exemple dans le Rommenal de Sone de Nansay (c. 1280) ${ }^{31}$. Est-ce à dire que pour Adenet aussi les compétences musicales ne sont plus que secondaires ? S'il est difficile d'être très affirmatif sur ce point, il me semble néanmoins tout aussi difficile de soutenir avec A. Henry qu'Adenet était «avant tout musicien $»^{32}$, d'autant qu'une dernière série d'indices, cette fois d'ordre iconographique, semble aller dans le même sens.

Le manuscrit 3142 de la Bibliothèque de l'Arsenal, outre qu'il est le seul, comme nous le rappelions en introduction, à contenir les quatre compositions connues d'Adenet le Roi, se distingue par une autre particularité : il contient plusieurs enluminures représentant indubitablement le ménestrel en personne, dont quelques traits peuvent nous permettre de compléter le portrait jusqu'à maintenant purement textuel que nous avons entrepris de tracer. À dire vrai, après le commentaire approfondi que lui ont consacré W. Azzam et O. Collet, il ne reste probablement plus grand-chose à dire de ce manuscrit, que l'on peut dater avec une certaine précision (c. 1285-1292), mais dont on n'ignore le destinataire (la reine de France Marie de Brabant?) ${ }^{33}$; tout au plus tenterons-nous d'ajouter quelques remarques de détail concernant l'enluminure de son premier folio.

Comme l'ont donc bien montré W. Azzam et O. Collet, le manuscrit 3142 témoigne au premier chef, à la fin du XIII ${ }^{\mathrm{e}}$ siècle, de "l'émergence d'une conscience et d'une perception nouvelles de la figure de l'auteur $\aleph^{34}$, et ce à plusieurs niveaux : d'abord parce que l'attribution à un auteur est un principe de classement dans le manuscrit, qui comporte plusieurs corpus plus ou moins complets, outre celui d'Adenet; ensuite parce que plusieurs des textes que consigne ce manuscrit citent le nom de leur auteur en l'associant à la première personne du locuteurcomme dans le prologue du Cleomadés -, phénomène plutôt exceptionnel ; enfin par son programme iconographique, où la représentation du poète, sous deux espèces essentiellement («l'auteur-orateur» et «l'auteur au travail»), occupe une place particulièrement importante. Adenet le Roi, pour nous en tenir à lui, est ainsi

\footnotetext{
${ }^{31}$ Sur ces personnages de ménestrels, voir notre Jongleur dans la littérature narrative des XII ${ }^{e}$ et XIII ${ }^{e}$ siècles, Paris, Champion, 2005.

${ }^{32}$ A. Henry, Les Euvres d'Adenet le Roi, tome un, p. 51.

${ }^{33}$ W. Azzam et O. Collet, « Le manuscrit 3142 de la Bibliothèque de l'Arsenal. Mise en recueil et conscience littéraire au XIII ${ }^{\mathrm{e}}$ siècle », Cahiers de civilisation médiévale, 44, 2001, p. 207-245. Voir aussi S. Huot, From Song to Book. The Poetics of Writing in Old French Lyric and Lyrical Narrative Poetry, Cornell University, 1987, p. 39-45.

${ }^{34}$ W. Azzam et O. Collet, art. cit., p. 219.
} 
représenté pas moins de quatre fois dans le manuscrit : au recto du premier folio, d'abord dans une grande miniature occupant le quart supérieur gauche de la page (sur laquelle nous allons tout de suite revenir), puis dans une initiale historiée qui montre le poète en train d'écrire sur des tablettes; au folio $72 \mathrm{r}^{\circ}$, dans une petite miniature, Adenet offre son livre au comte Robert II d'Artois ; enfin au folio $73 \mathrm{r}^{\circ}$, au début des Enfances Ogier, une initiale historiée représente à nouveau le poète en train d'écrire, cette fois sur un manuscrit ${ }^{35}$. "Ainsi, comme le notent finalement W. Azzam et $\mathrm{O}$. Collet, les représentations d'Adenet le Roi concentrent à elles seules à peu près toutes les étapes de l'élaboration et de la maîtrise d'une œuvre par son auteur, de l'inspiration ou des ébauches préliminaires jusqu'au don, voire peut-être à la récitation orale, en passant par l'écriture proprement dite $»^{36}$.

Revenons maintenant à la grande miniature de frontispice, qui montre, sur un fond à damier bleu, rouge et or, trois figures régulièrement disposées au premier plan : à gauche et debout, Adenet le Roi, reconnaissable à sa couronne et à la vielle qu'il tient dans sa main droite (sa main gauche est tendue), ainsi qu'à la robe grise à capuchon qu'il porte, humble vêtement comparé à celui de ses voisins ; au milieu et à droite, assis sur des coussins, deux personnages richement vêtus, un homme et une femme portant couronne (et tendant la main droite), que leur robe armoriée permet d'identifier avec Jean II de Brabant et Blanche de Castille. Au second plan, étendue sur un lit, derrière Blanche de Castille, se trouve Marie de Brabant, elle aussi reconnaissable aux armoiries qu'elle porte. Cette miniature, qui représente donc l'auteur de Cleomadés en compagnie des deux femmes qui le lui ont conmandé, a donné lieu à des interprétations quelque peu divergentes. D'après A. Henry, Marie de France, Jean II de Brabant et Adenet « écoutent Blanche, fille de saint Louis et veuve de l'infant de Castille, qui raconte les aventures de Cléomadès ${ }^{37}$. Selon $\mathrm{M}$. Clouzot, en revanche, c'est le poète qui « adresse le geste du récitant à la reine Marie de France» et ce sont « les deux femmes qui écoutent Adenet en compagnie de Jean II de Brabant $\wedge^{38}$. Quant à W. Azzam et O. Collet, ils mentionnent ces deux possibilités, sans toutefois résoudre la difficulté.

N'ayant pas la prétention d'apporter à ce petit problème une solution définitive, il nous paraît du moins possible de l'aborder sous un angle un peu différent, en tenant compte de l'ensemble de l'ornementation de la page ${ }^{39}$, et des deux, voire des trois Adenet qui s'y trouvent représentés, sans se laisser obnubiler par la grande miniature. Concernant cette dernière, si on laisse de côté la question de

\footnotetext{
${ }^{35}$ «Enfin, la lettre historiée des Enfances Ogier donne à voir l'auteur dans son travail effectif d'écrivain : devant un codex (ou, plus vraisemblablement, un bifolio) ouvert dont la page de gauche est couverte de traits verticaux réguliers qui symbolisent l'écriture, plume et scalpel en main, il corrige son texte $»$ (ibid., p. 223).

${ }^{36}$ Ibid.

${ }^{37}$ A. Henry, Les CEuvres d'Adenet le Roi, tome un, p. 96-97.

${ }^{38}$ M. Clouzot, notice 83 du catalogue de l'exposition Moyen Âge entre ordre et désordre, Paris, Cité de la musique / Réunion des musées nationaux, 2004, p. 202.

${ }^{39}$ On trouvera une belle et grande reproduction de l'ensemble de la page dans l'ouvrage cité ci-dessus, p. 203.
} 
savoir si Adenet écoute ou parle ${ }^{40}$, on notera surtout que si le ménestrel tient bien une vielle dans sa main droite, il n'en joue pas; certes, l'instrument sert ici (uniquement?) à signaler le ménestrel, mais n'en reste pas moins qu'Adenet apparaît d'emblée, dans le manuscrit qui rassemble ses œuvres, comme un ménestrel dépourvu de musique, ou pour qui la musique n'est plus qu'accessoire ${ }^{41}$. La position de ce premier Adenet, dans le coin inférieur gauche de la miniature, fait immédiatement signe vers l'initiale historiée qui se trouve juste en-dessous, et contient un deuxième Adenet, en train d'écrire sur des tablettes de cire, soit qu'il prenne des notes en écoutant le récit de Blanche de Castille, soit tout simplement qu'il soit en train de composer son roman; comme on le voit dans d'autres représentations du poète (plus nombreuses que la seule où il apparaît doté d'une vielle), Adenet est donc bien un ménestrel qui écrit, un ménestrel escrivain. Enfin, à la toute extrémité d'un long rinceau qui part de l'initiale historiée et descend jusqu'au coin inférieur droit de la page, se trouve - malheureusement très effacé un personnage en train de jouer de la vielle: une troisième figuration d'Adenet, représentant, dans les marges du manuscrit, ce que le poète n'est plus que de façon marginale, un musicien ${ }^{42}$ ? Ce ne serait pas pour surprendre, à une époque (entre Baudouin de Condé et Watriquet de Couvin) où le droit menestrel est un poète qui tend de plus en plus à situer ses moyens spécifiques du côté des mots (qui vont se séparer progressivement de la musique au cours du XIV ${ }^{\mathrm{e}}$ siècle), de l'autorité morale qu'ils peuvent représenter, et de l'écriture qui les recueille et les pérennise.

\section{Conclusion}

Le cas d'Adenet le Roi, plutôt qu'exceptionnel, est sans aucun doute symptomatique d'une évolution qui se produit au tournant des $\mathrm{XIII}^{\mathrm{e}}$ et $\mathrm{XIV}^{\mathrm{e}}$ siècles dans le statut du poète, ses compétences et ses représentations ${ }^{43}$. Pour ne citer qu'un autre exemple comparable - et d'autant plus comparable que les carrières de ces deux poètes sont indéniablement proches, puisqu'ils se sont illustrés dans les mêmes genres, chanson de geste et roman (quoique dans un ordre inverse), ont travaillé la

\footnotetext{
${ }^{40}$ Mentionner le «geste du récitant» d'Adenet, comme le fait M. Clouzot, ne permet pas de résoudre le problème, puisque de son côté et symétriquement, Blanche de Castille fait exactement le même geste, marquant probablement, en effet, une prise de parole; peut-être la solution réside-t-elle dans la possibilité que les deux personnages soient bien en train de parler, mais pas dans la même temporalité, même si l'image les réunit : c'est d'abord Blanche de Castille qui raconte l'histoire de Cléomadès, puis Adenet qui en restitue le roman devant son noble public.

${ }^{41}$ À moins - autre interprétation possible - que la vielle n'entre en jeu qu'à certains moments de la récitation d'Adenet, par exemple pour accompagner les quelques insertions lyriques que comporte le roman; mais c'est peut-être prêter à l'enlumineur une connaissance un peu trop précise du texte...

${ }^{42}$ Noter que l'on retrouve au folio $73 \mathrm{r}^{\circ}$ du manuscrit le même type de rinceau partant de l'initiale historiée représentant Adenet en train d'écrire, et portant également à son extrémité un jongleur en train de jouer de la vielle, en outre pourvu cette fois-ci d'une couronne.

${ }^{43}$ Pour bien situer Adenet le Roi dans ce contexte, voir S. Huot, op. cit., en particulier p. 211241.
} 
même matière pour aboutir à Cleomadés et Meliacin, deux romans jumeaux composés pour le même cénacle royal $^{44}$-, on trouve aussi dans les trois œuvres conservées de Girart d'Amiens de longs prologues (et épilogues) qui, tout en maintenant à peu près les distinctions génériques traditionnelles, relèvent de la même mise en avant du nom de l'auteur, associé à une première personne pleinement affirmée ${ }^{45}$.

Chez Girart d'Amiens, cependant, la mention des mécènes ne tourne pas au long excursus autobiographique, comme dans l'épilogue du Cleomadés; on ne trouve pas dans Meliacin de personnage de ménestrel (où le rôle équivalent à celui de Pinçonnet est tenu par un vilain serviable); et aucun des manuscrits qui nous conservent son œuvre ne comporte d'enluminure comparable à celle qui ouvre l'Arsenal $3142^{46}$. C'est là peut-être la preuve, ou du moins le signe, qu'à côté des

${ }^{44}$ A. Saly, «Écrivains mystificateurs : le cas d'Adenet le Roi et de Girart d'Amiens », Figures de l'écrivain au Moyen Âge, éd. D. Buschinger, Göppingen, Kümmerle, 1991, p. 245-253.

${ }^{45}$ Par exemple : «Pour coi Gerardinz apenssez / S'est d'un bel conte en rime metre », et plus loin «Et je, Gerars, sans contredit...» dans le prologue d'Escanor (éd. R. Trachsler, Genève, Droz, 1994, tome un, v. 4-5 et 50); «Et je, Girars d'Amiens, qui touz sui desirans / De faire son plaisir de cuer liez et joians, / Ai fait ce livre ci, dont fais me fu commans » dans L'Istoire le roy Charlemaine (éd. D. Métraux, Lewiston, Edwin Mellen, 2004, tome trois, v. 1921919221).

${ }^{46}$ Nous nous appuyons pour ce constat sur G. J. Brault, «Les manuscrits des œuvres de Girart d'Amiens », Romania, 80, 1959, p. 433-446. Toutes les miniatures des différents manuscrits ne sont malheureusement pas décrites dans cet article, mais apparemment aucune d'entre elles ne peut se comparer à celle de l'Arsenal 3142, sinon la grande enluminure qui ouvre les manuscrits BNF, fr. 1589 et fr. 1633 de Meliacin, mais cette dernière ne représente qu'un parterre de nobles, sans le moindre ménestrel. Voir sur ce point A. Saly, «Les manuscrits du Meliacin de Girart d'Amiens » (Travaux de linguistique et de littérature, 18, 2, 1980, p. 23 35 ) et «Les destinataires du roman de Meliacin» (Travaux de linguistique et de littérature, 
accidents de l'histoire (si aucun manuscrit rassemblant la totalité des œuvres de Girart ne nous est parvenu, on ne doit pas en déduire qu'un tel manuscrit n'a jamais existé) et des causes structurelles (une évolution globale dans les représentations de l'auteur à la fin du XIII ${ }^{\mathrm{e}}$ siècle et au début du XIV ${ }^{\mathrm{e}}$ siècle), il faut aussi faire la part des causes individuelles, laissant à penser qu'Adenet le Roi- quoique «fonctionnaire subalterne [jouissant] à peine d'un peu plus de considération que les fauconniers ou les bouteilliers », comme le rappelle A. Henry ${ }^{47}-$ n'avait pas une assez piètre opinion de lui-même pour ne pas s'engager dans ce mouvement de promotion de l'auteur dont il constitue un des témoins, et peut-être un des moteurs privilégiés.

Silvère Menegaldo Université d'Orléans

19, 2, 1981, p. 7-16).

${ }^{47}$ A. Henry, Les Cuvres d'Adenet le Roi, t. 1, p. 49. 


\title{
rin
}

\section{Berte as grans piés et l'abolition des frontières génériques chez Adenet le Roi}

\begin{abstract}
Contrary to the so-called Adenet le Roi's other works, Berte as grans piés appears to be an ambiguous, hybrid text, that tends to disappoint the reader at every turn and seems at first to be put together in a very haphazard way. From the prologue on, the narrator takes liberties with the acknowledged topoi that define literary "genres" in the $13^{\text {th }}$ century. He handles his - rather motley - materials in a manner that leads the reader to wonder about the "meaning" (senefiance) of Berte's adventures, as wife to king Pepin and future mother to Charlemagne, and about the generic nature of this text, neither romance nor chanson de geste, nor saint life - but something of each.

Résumé : À la différence des autres auvres du trouvère que l'on appelle Adenet le Roi, Berte as grans piés se présente comme un texte ambigu, hybride, qui ne cesse de décevoir les attentes du lecteur et se construit, semble-t-il de prime abord, " en dépit du bon sens ». Dès le prologue, le narrateur prend un certain nombre de libertés par rapport aux topoi génériques en vigueur, et la manière dont il traite le matériau - relativement hétéroclite, d'ailleurs dont il dispose conduit à s'interroger sur la senefiance de l'aventure improbable de Berte, épouse du roi Pépin et future mère de Charlemagne, ainsi que sur le genre dont relève en définitive ce texte qui n'est ni roman, ni chanson de geste, nie vie de sainte, mais un peu des trois à la fois.
\end{abstract}

Adenet le Roi constitue une énigme pour le médiéviste : à première vue, l'existence de ce trouvère de la seconde moitié du XIII ${ }^{\mathrm{e}}$ siècle, doté d'une bibliographie de quatre titres non discutés, est une aubaine pour une critique en mal de personnalités stables dans le monde des lettres de cette époque. Malheureusement, un examen plus approfondi de l'œuvre attribuée à Adenet révèle l'existence de questions, voire de difficultés, quasiment insolubles au niveau de la répartition générique ${ }^{1}$. Si personne ne discute la qualité de "roman » de Cleomadés, dont il existe d'ailleurs un double presque parfait dû à la plume de Girart d'Amiens, le Meliacin lui aussi identifié sans hésitation comme roman, les choses se gâtent dès qu'on aborde les trois autres, à savoir Berte as grans piés, les Enfances Ogier, et Buevon de Commarchis. S'il faut absolument leur attribuer une étiquette, c'est à celle de chanson de geste qu'on a recours - et les deux derniers ouvrages, tout du moins, satisfont à la majorité des critères définitoires de ce genre. Certes, Buevon ne peut être rattaché à aucun cycle épique connu, et les Enfances Ogier abordent sous un angle inattendu la carrière d'un héros relativement atypique. Ces écarts sont cependant mineurs lorsqu'on les compare à ceux que dénote Berte as grans piés.

\footnotetext{
${ }^{1}$ Pour une introduction générale à l'œuvre d'Adenet et l'édition du texte qui nous occupe ici, voir A. Henry, Les Euvres d'Adenet le roi. T. 1. Biographie d'Adenet. La Tradition manuscrite, Bruges, De Tempel, 1951 ; et Les Euvres d'Adenet le Roi. T. 1V. Berte aus grans piés, Bruxelles, Presses universitaires de Bruxelles, 1963.
}

Cahiers de Recherches Médiévales, 18, 2009 
Si l'on part de l'idée simple, voire simpliste, que la chanson de geste est une œuvre épique dépeignant les affrontements guerriers entre Chrétiens et Sarrasins, ou parfois, comme dans le Cycle des Barons révoltés, entre vassaux et suzerain, ou entre deux lignages, Berte ne peut qu'être trouvée insuffisante: pas une seule bataille, pas trace de conflit entre états ou entre personnes. L'intrigue relève entièrement de la sphère du privé. Néanmoins, les personnages centraux, la reine Berte et le roi Pépin, se rattachent indubitablement à la "matière de France», puisque ce sont, officiellement, les parents de Charlemagne, et on retrouve, en mineur, certaines autres figures épiques, comme le très jeune Naime, qui sera, bien plus tard, le fidèle conseiller de l'empereur. La nomenclature ne saurait toutefois suffire à déterminer le genre auquel appartient un texte, d'autant que dans ce cas les informations qu'elle fournit ne sont pas dépourvues d'ambiguïté : en effet, le roi et la reine de Hongrie, les parents de la jeune Berte, sont appelés Floire et Blanchefleur, comme les héros d'un "roman idyllique» du XII ${ }^{\mathrm{e}}$ siècle $^{2}$. Faire de Berte as grans piés un roman paraît plus satisfaisant... à condition de ne pas s'arrêter à la forme du texte, composé de laisses d'alexandrins assonancées. Mais, si nous sommes en présence d'un roman, de quel type de roman s'agit-il? Les souverains de Hongrie n'ont de commun que le nom avec le jeune fils du sultan de Galice et la fille de son esclave chrétienne, dont les aventures se déroulent dans un Orient à moitié imaginaire, et non au cœur de l'Europe. Le motif de la fiancée substituée remplace l'argument des amours enfantines dans le texte d'Adenet; tout au plus pourrait-on repérer un certain parallélisme dans le thème de la "fausse mort » qui figure dans les deux œuvres - mais de manière en définitive variée. On aurait plutôt, a priori, plus de chance du côté de l'hagiographie, puisque certains choix de l'héroïne correspondent à ceux d'une sainte cherchant à échapper à des soupirants indésirables. Néanmoins, Berte n'est pas une sainte, les raisons pour lesquelles elle décide de préserver sa virginité tout en dissimulant son identité ne sont pas très claires, et certains aspects du dénouement sont en contradiction flagrante avec une perspective hagiographique. En définitive, on ne peut que conclure dans le cas de Berte as grans piés à une volonté délibérée d'hybridation de la part d'un auteur qui ne suscite les attentes de son lecteur que pour mieux les décevoir.

Regardons les choses d'un peu plus près. D'emblée le prologue témoigne d'une curieuse hétérogénéité de la matière :

[...] le livre as estoires me moustra et g'i vi

L'estoire de Bertain et de Pepin aussi

Comment n'en quel maniere le lion assailli ;

[...] la vraie estoire emportai avoec mi,

Si com Berte fu en la forest par li,

Ou mainte grosse paine endura et soufri. (v. 10-12 et 17-19)

\footnotetext{
${ }^{2}$ Voir la récente édition de J.-L. Leclanche: Robert d'Orbigny, Le Conte de Floire et Blanchefleur, Paris, Champion «Classiques », 2003.
} 
L' «histoire de Berte et de Pépin»-de Pépin «aussi », ce qui ne manque pas d'insister sur la qualité de protagoniste de la seule Berte - est associée à l'aventure du lion, dont le moins que l'on puisse dire est qu'elle occupe une place réduite dans le récit. En fait, la présentation d'Adenet est doublement trompeuse, puisque le lecteur est naturellement porté à supposer à la fois que l'épisode du lion sera largement développé, et que le fauve va rencontrer Berte dans la forêt où elle subit de si grandes souffrances. En outre, après cette laisse programmatique et apologétique (nous y reviendrons dans un instant), la narration démarre en amont du sujet annoncé, au temps de Charles Martel, de son épouse (qui reste anonyme, comme on pouvait s'y attendre), et de leurs deux fils, Carloman, bel exemple de chevalier qui se retire du monde pour devenir moine dans un monastère, et Pépin, le héros désigné de l'œuvre à venir. Les qualificatifs décernés à Charles Martel sont à la limite du péjoratif («fels et fiers et de grant estoutie »), les allusions à ses combats victorieux contre un parti opposé mené par «Gerart et Foucon » ${ }^{3}$ tournent court puisque cette guerre s'achève en quatre vers, et la référence insolite aux Vandales ( «Wandres ») est en quelque court-circuitée par un motif de «reverdie» qui nous amène à une scène de cour pendant laquelle le fameux lion va s'échapper, et le roi Charles Martel s'enfuir de manière fort peu glorieuse.

La troisième laisse présente des caractéristiques analogues: elle boucle l'histoire du lion, sans en tirer de conclusions particulières, expédie ad patres Charles Martel et sa femme, et traite du premier mariage de Pépin sans pour autant mentionner le nom de son épouse ${ }^{4}$. Il est difficile à première lecture de déterminer si les peines endurées par le roi du fait de cette union sont causées par les guerres qu'elle a suscitées ou par l'absence persistante d'héritier au fil des années. Un brusque changement de registre intervient à la mort de cette première compagne, puisque le trouvère choisit de développer ici le motif des barons poussant au mariage de leur seigneur et proposant des fiancées possibles : motif romanesque par excellence, alors que l'intertexte affleurant jusque là était fortement épique, mais aussi motif quelque peu "bâclé » puisque Pépin n'émet aucune objection quand on lui propose la fille du roi de Hongrie, et que les parents de la jeune fille donnent immédiatement leur consentement. Au vers 184 du texte, on a déjà parcouru plusieurs ébauches de scénario qui auraient pu suffire à composer une chanson de geste ou un roman de dimensions modestes. Et rien, cependant, ne permet de déterminer vers quel «genre» l'œuvre va se tourner, ni quel matériau elle va exploiter, après avoir si rapidement «écrémé» de nombreuses séquences préexistantes.

Ce début non dépourvu de virtuosité a peut-être pour fonction de souligner la valeur de l'écrivain en mentionnant avec une feinte désinvolture une large gamme

\footnotetext{
${ }^{3}$ Qu'il s'agisse ou non de Girart de Roussillon et de Fouque, son cousin et allié, est ici d'une importance secondaire. L'essentiel est l'espèce de «consumérisme » acharné dont fait preuve Adenet, brûlant sans les exploiter des ressources considérables dans la première laisse narrative de son œuvre.

${ }^{4}$ On mentionne son lignage, et les guerres liées à cette alliance, mais de façon très elliptique : «Sa femme fu estraite, sans mençonge parler, / De Gerbert, de Gerin, de Malvoisin le ber. / A Fromont orent guerre, ch'avez oÿ conter, / Dont il couvint de cors mainte ame dessevrer, / Maint chastel, mainte tour a terre craventer, / S'en couvint a Pepin mainte paine endurer » (v. 90-95).
} 
de sujets qui témoignent de sa culture. Mais il témoigne aussi d'une sorte d'hésitation au niveau générique. Les motifs qui s'enchaînent dans les laisses initiales tendent à se rapprocher davantage de la topique romanesque que de celle des chansons de geste traditionnelles. La laisse prologue elle-même reprend et module la plupart des topoi de la mise en écrit présents dans les romans du XII ${ }^{\mathrm{e}}$ siècle :

A l'issue d'avrill, un tans douç et joli, Que herbeletes pongnent et pre sont raverdi Et arbrissel desirent qu'il fussent parflori,

Tout droit en cel termine que je ici vous di, A Paris la cité estoie un venredi ;

Pour ce qu'il ert devenres, en mon cuer m'assenti

K'a Saint Denis iroie por priier Dieu merci.

A un moine courtois, c'on nonmoit Savari,

M'acointai telement, Damedieu en graci,

Que le livre as estoires me moustra et g'i vi

L'estoire de Bertain et de Pepin aussi.

[...]

Aprentiç jougleour et escrivain mari,

Qui l'ont de lieus en lieus ça et la conqueilli,

Ont l'estoire faussee, onques mais ne vi si.

Ilueques demorai de lors jusqu'au mardi

Tant que la vraie estoire enportai avec mi.

$[\ldots]$

L'estoire iert si rimee, par foi le vous plevi,

Que li mesentendant en seront abaubi

Et li bien entendant en seront esjoy. (v. 1-11, 12-17 et 20-22)

Quelques détails, toutefois, marquent d'emblée l'écart par rapport au «profil» classique de l'œuvre et de l'écrivain. Ainsi, le motif de la "reverdie» aboutit curieusement, non à une scène courtoise, mais à une visite à l'abbaye de SaintDenis, pour y prier étant donné qu'on est vendredi. La rencontre «courtoise » a lieu toutefois, mais le personnage qui se voit attribuer cette épithète est, paradoxalement, un moine, un moine dont le narrateur anonyme, bien qu'extrêmement présent par le biais d'une série de pronoms et de formes verbales de première personne, fournit obligeamment le nom tout en plaçant leurs relations sur un plan un peu déconcertant. En effet, «s'accointer de», en règle générale, n'est pas un terme que l'on emploie $\mathrm{au} \mathrm{XIII}^{\mathrm{e}}$ siècle pour définir un lien en quelque sorte professionnel - entre deux «clercs» dont l'un montre un manuscrit à l'autre comme s'il s'agissait de lui concéder une faveur amoureuse. Pourtant, la mention de "Savari » apparaît en définitive ressortir à une stratégie déceptive, puisque loin d'élaborer sur cet étrange lien entre la personne d'énonciation et le «gardien » du texte, l'attention se détourne immédiatement vers «l'estoire»- ou plus exactement «le livre as estoires». La nuance est importante, puisqu'elle suggère l'existence d'autres histoires, momentanément laissées de côté, en réserve, en quelque sorte. Mais, dans ces conditions, pourquoi se focaliser sur celle de Berte, augmentée du codicille «Pepin 
aussi », et de la référence au lion, dont le rôle est si mineur dans la suite du récit ? De la sorte, les vers programmatiques se révèlent comme au moins porteurs d'une information tronquée, sinon délibérément trompeurs.

La référence aux rivaux incompétents, quant à elle, est parfaitement dans la norme, et se rencontre dans à peu près tous les genres narratifs, du Tristan de Thomas à la Vie de saint Thomas Becket de Guernes de Pont-Sainte-Maxence ${ }^{5}$ - et à des « chansons de geste » relativement tardives comme Huon de Bordeaux. Tout au plus pourrait-on voir un signe des temps dans la mention, au côté des mauvais "jougleour», de mauvais "escrivains", comme si la profession de rapporteur d'histoires se divisait désormais en deux catégories parallèles, correspondant aux formes orales et aux formes écrites d'une littérature en devenir. Mais si la revendication de supériorité du narrateur-auteur de l'œuvre en cours de présentation est parfaitement conforme au code en vigueur et à l'attente du public au sens le plus large, les détails qui suivent font fortement pencher la balance du côté du « roman », en évacuant les références à une possible oralité.

Ce qui est d'abord très perturbant, en effet, c'est le fait que le «je» en position de force dans le système d'énonciation se vante d'avoir emporté la « vraie» histoire avec lui - c'est-à-dire, d'en avoir pris copie dans l'intervalle de temps qu'il précise, du vendredi au mardi. En précisant qu'il va en donner une version rimée, ce «scribe» toujours anonyme, dont on peut même dire qu'il se dissimule derrière le seul nom de personne non fictive fourni dans ce prologue, à savoir celui de Savari (pourquoi donner le nom d'un second rôle qui disparaît aussitôt après avoir été mentionné et pas celui du «copiste» ou compilateur?), accède au statut d'auteur à part entière, ajoutant sa " griffe» au matériau brut, et par inférence en prose, qu'il a rapporté de l'abbaye. L'attention portée à la transmission de la chose littéraire a acquis un certain degré de sophistication au temps d'Adenet: il ne suffit plus de renvoyer le lecteur à une bibliothèque où il pourra voir l'original du texte qu'il est en train de lire, ou de mentionner casuellement le livre fourni par un commanditaire ${ }^{6}$. La séquence de micro-narration, décrivant les circonstances de la rencontre avec la version authentique de l'«estoire» et celles de sa transformation

\footnotetext{
${ }^{5}$ Thomas signale, au début de l'épisode de Tristan le Nain, qu'il existe plusieurs versions divergentes de l'histoire; il critique violemment celles de ses rivaux, qui pèchent, dit-il, par invraisemblance (voir Thomas d'Angleterre, Tristan et Yseut, v. 2266-2310, dans Tristan et Yseut. Les premières versions européennes, éd. Ch. Marchello-Nizia, Paris, Gallimard "Pléiade", 1995). Guernes se plaint d'abord spécifiquement que des rivaux inconnus lui ont volé son "premier jet » et l'ont diffusé avant qu'il n'ait le temps de le polir et raffiner. Mais de manière plus générale, il affirme péremptoirement: «Tut cil autre romanz ke unt fait del martyr / Clerc u lai, muine u dame, mult les oï mentir, / Le veir ne le plain nes i oï furnir. / Mes ci purrez le veir e tut le plain oïr ; / N'istrai de verité pur perdre u pur murir » (v. 161165 ; voir Guernes de Pont-Sainte-Maxence, La Vie de Saint Thomas Becket, éd. E. Walberg, Paris, Champion, 1936 et sur $<$ http://www.anglo-norman.net/texts/becket-contents.html $>$ ). ${ }^{6}$ Voir, pour ces deux cas de figure, Chrétien de Troyes : dans le prologue d'Erec et Enide, il affirme que l'histoire dont il va faire un livre se trouve «En un des livres de l'aumaire / Mon seignor saint Pere a Biauvez» (v. 18-26 pour le passage intégral), et dans celui du Conte du Graal il se réfère au livre que lui a donné son «patron» Philippe de Flandres («Ce est li contes del graal, / Dont li cuens li bailla le livre», v. 94-95). Voir Chrétien de Troyes, Euvres complètes, éd. D. Poirion, Paris, Gallimard "Pléiade", 1994.
} 
en texte littéraire, correspond davantage à une esthétique de la vraisemblance qui trouvera, en un sens, son développement complet dans le prologue historicolinguistique du Perceforest ${ }^{7}$. L'attention à la forme, "ryme» vs prose, se substitue simplement dans ce cas à l'attention aux langues (du grec au latin, du latin au breton, du breton au français...). Néanmoins, alors que ces indices nous orientent vers une lecture générique de type «roman», les deux derniers vers du prologue réintroduisent l'oralité, en même temps qu'ils suggèrent une exigence de l'auteur vis-à-vis de son public: les deux catégories présentées sont toutes deux des catégories d'auditeurs, mais il y en a de bons, et de mauvais. L'interaction entre l'auteur-prestataire de l'œuvre et ses consommateurs reconduit donc la dichotomie entre bons et mauvais «jongleurs» ou écrivains; elle fonde en droit une revendication de qualité, mais elle fonctionne aussi comme une marque de maîtrise de la part de la première personne d'énonciation: si ceux qui n'apprécient pas l'œuvre sont «mesentendant», cela signifie que le rapport d'autorité va de l'«auteur » à l'auditeur, et non l'inverse, comme on pourrait s'y attendre dans le cadre d'une littérature «sur commande», ou d'une performance où l'«acteur» dépend de la bonne volonté de son audience.

Cependant, malgré tout, ce qui se dégage de ce «pré-récit» chaotique, c'est une impression décidément romanesque, qui confirme l'originalité du vers 11: l'histoire sera avant tout celle de Berte, et ses tribulations, comme l'annonce le vers 178 , seront causées par une autre femme, «la serve», et non par un conflit guerrier entre lignages ou nations. Il appert dans la suite que le modèle, toutefois, n'est pas exactement celui qu'on attendrait : si Adenet joue sur sa maîtrise de l'intertexte, il traite avec une certaine désinvolture les lois du genre qu'il prétend illustrer, en multipliant les références à une " estoire» très éloignée du répertoire des chansons de geste, celle de Tristan - ou plutôt, comme le dirait Chrétien de Troyes, celle « du roi Marc et d'Yseut la Blonde». En effet, quels sont les partenaires d'un mariage royal apparemment voué au désastre? Un roi veuf, que l'on peut donc supposer plus âgé que sa nouvelle fiancée, et une princesse lointaine, qu'il décide d'épouser sur la seule réputation de sa beauté, chantée par ses barons qui veulent absolument un héritier.

Là-dessus, si l'épisode de l'ambassade auprès des souverains de Hongrie (Floire et Blanchefleur, donc, ces «indices» d'un autre système de référence brutalement implantés dans l'espace carolingien) est traité efficacement, sans fioritures excessives, le lecteur n'en est pas moins surpris par le chagrin spectaculaire dont témoigne la jeune Berte. Ses parents acceptent sans hésitation de la laisser épouser Pépin, l'existence d'un frère et d'une sœur garantissant le prolongement de leur propre lignage; à la cour de Hongrie, où la langue «de culture » est le français - élégant détail qui court-circuite les traditionnelles difficultés linguistiques des voyageurs de l'époque et la nécessité des «truchements»-, personne ne semble avoir besoin d'une princesse supplémentaire. En revanche, Berte elle-même ne paraît pas du tout sensible à l'honneur qui lui est fait; elle n'intervient dans le texte que pour manifester une profonde douleur, à chaque fois qu'elle se trouve en position de sujet grammatical :

${ }^{7}$ Voir Perceforest. Première partie, éd. G. Roussineau, Genève, Droz, 2007, p. 69-73 (§§ 80$85)$. 
Berte la debonaire, qui n'ot pensee avere,

Molt durement plorant prent congié a son pere. (v. 135-136)

Ou encore :

Le jour que ele dut sa voie avoir emprise

S'est devant le roi Floire son pere a genols mise,

En plorant prent congié sans mal et sans faintise. (v. 170-172)

Et pour finir, juste avant la mention des larmes des «gens de cele terre», au moment du troisième et dernier « congé » :

Quant Berte ot pris congié a son pere au cuer vrai,

Forment li duelt li cuers, molt fu en grant esmai. (v. 179-180)

D'autres manifestations de deuil interviennent au moment de la séparation entre la mère et la fille, ou entre Berte et sa sœur, la reine et la princesse s'évanouissant toutes deux de douleur.

Quelques détails supplémentaires contribuent à étayer les soupçons que le lecteur peut concevoir à l'égard de cette famille secrètement dysfonctionnelle : le père auquel Berte témoigne un attachement si intense lui recommande de continuer à ressembler à sa mère ${ }^{8}$, la jeune fille le prie de saluer de sa part son frère, étrangement absent de la scène des adieux, et la reine confie à son enfant la « serve» Aliste, avec sa mère Margiste et son cousin Tybert, en insistant sur le fait qu'elle aime d'autant plus Aliste que celle-ci ressemble vraiment beaucoup à Berte ! Bien sûr, ce motif de la ressemblance entre une « vraie» et une «fausse » reine rappelle immédiatement l'épisode célèbre du Lancelot, où la «Fausse Guenièvre » vient à la cour d'Arthur accuser sa demi-sœur d'usurpation et de tentative de meurtre'. Néanmoins, puisque personne à la cour de France ne connaît aucune des deux jeunes femmes, et que d'autre part la résolution de la crise repose précisément sur le fait qu'il existe un moyen imparable de les différencier, on ne voit pas très bien l'intérêt

${ }^{8}$ L'attachement réciproque de Berte et du roi Floire a une tonalité quasiment incestueuse, que vient cependant contredire la présence de la reine Blancheflour, mère de l'une et épouse de l'autre, alors que dans la plupart des scénarios de ce type, la mère de l'héroïne est morte, et son père décide de l'épouser à son tour en remplacement de sa première femme, à laquelle elle ressemble étonnamment. Ce schéma narratif, qui est celui de La Manekine, affleure peutêtre ici tout simplement parce que le roi Floire est le souverain de Hongrie, comme le père de l'infortunée Joïe dans l'œuvre de Philippe de Rémi (Philippe de Rémi, Le Roman de la Manekine, éd. A. Stones et R. Middleton, Amsterdam, Rodopi, 1999).

${ }^{9}$ Pour cette séquence du Lancelot, voir La Fausse Guenièvre (Lancelot du Lac III), éd. et trad. F. Mosès, Paris, Livre de Poche "Lettres Gothiques", 1998. On trouve dans Les Premiers faits du roi Arthur le «récit des origines » révélant l’identité et les circonstances de la naissance de l'«autre» Guenièvre, et relatant une première tentative de substitution juste avant la nuit de noces qui est assez proche de l'histoire racontée par Adenet (voir Le Livre du Graal, volume 1, éd. Ph. Walter et alii, Paris, Gallimard "Pléiade", 2001). 
de cet excursus, si ce n'est qu'il suggère une sorte de déficit dans l'amour maternel de la reine pour sa véritable fille ${ }^{10}$.

Quoiqu'il en soit du réseau de relations familiales et para-familiales à la cour de Hongrie, le récit revient en toute hâte en France, et marie Berte à Pépin sans même suggérer une rencontre préalable entre les deux personnages : le mariage est célébré à la laisse $\mathrm{X}$, «tout le monde» admire Berte, et celle-ci est désormais désignée par son titre: «la reine». Le «trouvère» Adenet trouve moyen de s'attarder sur les festivités qui suivent la cérémonie, en mentionnant par leur nom les deux principaux jongleurs qui viennent exercer leurs talents devant la jeune souveraine. Mais le roi Pépin brille par son absence, même lorsque l'on conduit Berte à sa chambre où on la laisse seule afin de ne pas trop la «travillier ». Làdessus, la «trahison » de Margiste, «l'orde vielle pullante», est annoncée en peu de mots, et sans la moindre explication: elle veut, sans doute, assurer l'avenir de sa fille, cette «seconde Berte» presque plus belle que la première, mais elle apparaît comme une caricature de traitresse, sans justification dramatique ni psychologique.

Afin de mener à bien son projet de "substitution d'épousée», elle fait d'obscures et menaçantes allusions à la mort qui attend l'objet des attentions du roi Pépin pendant la nuit de noces : elle a grand peur, dit-elle, que Berte n'y survive pas, et elle préfère mettre sa fille à sa place dans le lit conjugal, au risque de la perdre ${ }^{11}$. Dans la mesure où le péril n'est pas moindre pour la «serve» que pour la princesse $^{12}$, et où il n'est pas précisé en quoi ce péril est personnellement lié au roi Pépin, il semble clair que ce qui est en cause ici, c'est un rejet et une démonisation absolue de la sexualité : la consommation du mariage est perçue comme mortelle, dans tous les cas de figure. La réaction de Berte est éclairante; pour la première fois depuis son entrée en scène, elle passe des larmes au rire :

Grant joie ot la roÿne quant ele ot la maniere

Conment du roi Pepin se porra traire arriere. (v. 337-338)

Comme la suite le confirmera, Berte éprouve une véritable aversion pour la sexualité : sa préoccupation essentielle, quand elle vit avec la famille de Symon, est de préserver sa virginité, au point qu'elle faillit à son vœu et révèle sa véritable identité à Pépin au moment où celui-ci veut coucher avec elle. Si, par certains côtés, ce comportement nous rapproche d'un schéma hagiographique avec Berte dans le rôle de la sainte, il reste que dans le cadre d'un texte lignager dont le propos est précisément de raconter la venue au monde de celui sans lequel l'univers entier de la chanson de geste ne pourrait exister, ce refus du « devoir conjugal » apparaît comme un peu singulier.

\footnotetext{
${ }^{10}$ «[...] plus bele rien ne sai» (v. 186), dit la reine à propos d'Aliste, comme si la beauté de Berte était inférieure à celle de la "serve", et comme si vraiment la meilleure chose à faire quand on envoie une princesse à marier à un souverain qui ne la connaît pas était de lui adjoindre une suivante dont la beauté est susceptible d'éclipser la sienne propre.

${ }_{11}$ «J'aim mieus que ele muire que vous, mentir n'en quier» (v. 333), affirme-t-elle.

${ }^{12}$ Contrairement à ce qui se passe, par exemple, dans l'épisode du géant du Mont-SaintMichel dans le Brut, où la malheureuse Elaine ne peut survivre au viol par le géant alors que sa vieille nourrice peut satisfaire la sexualité du monstre sans difficulté.
} 
La suite de la séquence renforce ce malaise. Tout d'abord, il est bien précisé que Pépin, cette nuit-là, a rempli son rôle de chef de lignage :

Cele nuit fist li rois toute sa volenté

De la tres fausse serve, plaine de mauvaisté :

Un hoir i engendra [...] (v. 404-406)

Certes, il s'agit d'un «mauvais hoir», Rainfroi, son frère Heudri ne vaudra pas mieux, et tous deux seront éliminés par la suite de la généalogie. Mais on est en droit de s'interroger sur les mésaventures matrimoniales d'un roi dont le premier mariage est stérile, et qui engendre ensuite ses deux fils premiers nés en une femme d'origine servile, entièrement inappropriée pour cette fonction ${ }^{13}$. Ajoutons à cela que, lorsqu'il rencontre Berte dans la forêt, Pépin est immédiatement si "échauffé de luxure » qu'il s'en faut de peu qu'il ne la viole sur place, et qu'il lui offre en tout cas de devenir sa concubine officielle - en raison du petit problème légal qui lui interdit un troisième mariage. Les antécédents de Charlemagne sont rien moins que glorieux; notons d'ailleurs que lorsque, enfin, Pépin peut posséder Berte en toute légitimité ${ }^{14}$, ce n'est pas un fils qu'il engendre, mais seulement une fille - et qui plus est, une fille dont le nom rappelle la ruse et la tromperie, et dont la fonction essentielle est d'être la mère de Roland... ce qui n'est pas si positif que cela, à une époque où la paternité incestueuse de celui-ci est largement reconnue :

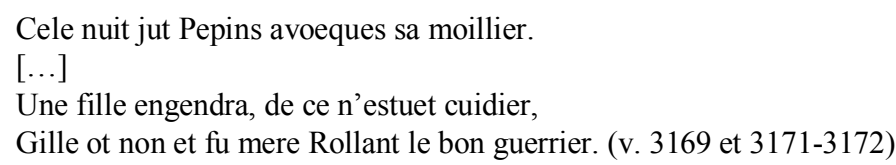

D'autre part, la mise en scène qui au petit matin aboutit, non pas comme dans la scène parallèle de l'«estoire de Tristan », à l'exclusion définitive de la véritable épouse et à sa condamnation pour tentative de meurtre souligne les aspects dangereux et réellement «sanglants» de toute activité sexuelle. Margiste a recommandé à sa fille de cacher un couteau dans le lit conjugal et de s'en blesser elle-même à la cuisse afin de faire croire que c'est Berte qui l'a lâchement attaquée : on ne saurait trouver métaphore plus parlante de l'horreur de la défloration! Chez Gottfried de Strasbourg, et sans doute chez Thomas d'Angleterre ${ }^{15}$, la substitution de

\footnotetext{
${ }^{13}$ D'un point de vue «historique», toutefois, on pourrait lire cette succession de mariages plus ou moins réussis de Pépin comme une tentative de la part d'Adenet de faire entrer dans un cadre romanesque conforme aux attentes du XIII ${ }^{\mathrm{e}}$ siècle les données brutes quelque peu dérangeantes dont on disposait à propos des princes carolingiens : concubinages notoires, répudiation d'épouses stériles ou devenues politiquement indésirables, reconnaissance officielle (et accession à l'héritage) de bâtards, etc.

${ }^{14}$ Précisons d'ailleurs que cette conception a lieu dans la forêt, c'est-à-dire dans l'espace sauvage où Pépin ne règne pas vraiment, comme pour renforcer l'aspect douteux de cette union : le roi n'a pas la tempérance nécessaire pour attendre d'être revenu «en France » et à la cour pour coucher avec sa femme.

${ }^{15}$ Voir Tristan et Yseut. Les premières versions européennes, p. 548-554 ; nous n'avons pas, malheureusement, le texte de Thomas pour cet épisode.
} 
Brangien à Yseut pour la nuit de noces est rendue nécessaire, non pas par un «défaut» du roi Marc, mais par le fait que la reine n'est plus vierge; et si Yseut décide de faire tuer sa suivante ensuite, c'est parce qu'elle craint que celle-ci n'ait tellement apprécié son expérience sexuelle avec Marc qu'elle ne désire prendre définitivement la place de sa maîtresse dans le lit du roi : on est donc en présence d'une conception de la sexualité diamétralement opposée à celle qui apparaît dans Berte as grans piés. Dans le texte d'Adenet, le seul moment que Berte passe dans le lit de ses noces est celui où, éberluée et menacée de mort par Margiste, elle est jetée en travers de la couche et liée par les serviteurs qui obéissent au roi : scène primitive d'horreur et d'incompréhension, qui rappelle d'une certaine manière ces fabliaux où la jeune épousée se soumet à toutes sortes de mauvais traitements parce qu'elle ne sait pas à quoi s'attendre de la part de son mari en guise de «consommation » du mariage $^{16}$.

L'épisode de Berte conduite dans la forêt pour y être mise à mort - son cœur devant être rapporté à Margiste - suit le schéma tristanien, dans lequel Yseut veut faire tuer Brangien (alors même que celle-ci lui a rendu un signalé service), mais aussi, de façon générique, le schéma des contes du type «Blanche-Neige» où une mauvaise reine / sorcière cherche à éliminer une jeune rivale. Adenet prend ses distances vis-à-vis du matériau folklorique qu'il réutilise, cependant, en laissant subsister dans les péripéties de la séquence un certain nombre d'incohérences ou de contradictions qui témoignent du peu d'importance qu'il accorde au scénario narratif per se. Ainsi, Tibert prend grand soin de nourrir et d'abreuver sa captive pendant leur voyage, même si pour ce faire il ne lui délie les mains que sous la menace de son épée... ${ }^{17}$ L'altercation entre Moran et Tibert, la « victoire» de Moran et de ses compagnons qui empêchent Tibert d'en finir avec Berte, mais acceptent de prétendre avec lui qu'ils ont accompli leur mission et que la jeune femme est morte, la « cote mal taillée» qui aboutit à l'abandon de Berte au milieu des terreurs d'une forêt "soutaine", tout cela suggère que l'auteur ne s'intéresse pas à ces aventures secondaires: ce ne sont que des hors-d'œuvre qui conduisent le lecteur aux véritables morceaux de bravoure du récit.

Ces morceaux de bravoure sont d'une part l'errance de Berte dans la forêt et son adoption par la famille du «forestier » Symon, d'autre part le voyage de la reine Blancheflour à Paris et sa découverte du subterfuge. Comme on l'a signalé, les trois premières laisses du texte consument une énorme quantité de matériaux narratifs, de quoi faire, sinon une chanson de geste pleine et entière, du moins un "premier vers » romanesque de taille conséquente. Le rythme se ralentit un peu par la suite, mais le voyage des ambassadeurs en Hongrie, les noces de Berte et Pépin, et les événements de la nuit de noce, jusqu'à, pour ainsi dire, l'arrivée de Berte à pied d'œuvre, dans la

\footnotetext{
${ }^{16}$ Inversement, suivant les conseils de Margiste, Berte «la debonaire» n'a vu aucune objection à passer sa «nuit de noces » en prières et en oraisons («En son lit en seant prist ses heures a dire, / Car bien estoit letree et bien savoit escrire», v. 402-403). Notons que le moment peut paraitre curieusement choisi pour signaler la «culture» de Berte, qui la rapproche, une fois de plus, d'un modèle de sainte lettrée, ou au moins de nonne instruite dans une abbaye.

${ }^{17}$ De même, pourquoi aller si loin pour mettre à mort la jeune femme, alors que le roi était tout prêt à ordonner une exécution publique ? Dans les contes traditionnels, l'élimination de la jeune fille doit se faire discrètement, en cachette du roi, justement.
} 
forêt sont expédiés en 22 laisses, et environ six cents vers, alors que l'errance de la jeune femme au milieu des bois s'étend sur 20 laisses, et plus de quatre cents vers, sans parler de sa rencontre avec l'ermite, qui la repousse, puis avec l'ourse qui la terrifie au point de la faire s'évanouir. Il ne se passe pourtant rien, dans ce long espace textuel: Adenet exploite au mieux la technique des laisses parallèles, reprenant indéfiniment, avec des variations mineures, la même situation et les mêmes commentaires, au point qu'il est difficile de se souvenir qu'en définitive Berte ne passe jamais qu'une nuit dans la forêt... L'héroïne est seule dans les bois, elle est privée du confort dû à son rang, elle a peur de la « sauvagine», elle prie Dieu et la Vierge de lui venir en aide : rien de plus, si ce n'est que l'auteur se complaît à la description de cette féminité éplorée - si touchante que l'ermite refuse de lui venir en aide, de crainte que la tentation ne soit trop forte pour sa vertu.

C'est là un motif hagiographique classique: soit que la demoiselle soit effectivement une tentatrice qui vient mettre à l'épreuve un saint homme, soit qu'elle désire se retirer du monde et n'en soit empêchée par des ermites peu vertueux $^{18}$. De même, l'accueil généreux que réserve à la pauvre errante Symon «le voier ", sa femme Constance et ses deux filles Ysabiaus et Aiglantine relève d'un topos du roman « réaliste»: on en rencontre une version très proche dans L'Escoufle de Jean Renart, par exemple ${ }^{19}$. Ce qui est beaucoup plus surprenant dans Berte as grans piés, c'est la manière obsessionnelle dont Berte s'obstine à dissimuler son identité, le vœu qu'elle fait de ne jamais révéler qu'elle est la fille du roi de Hongrie et l'épouse du roi de France, et pour finir sa satisfaction profonde à l'idée qu'elle n'est plus désormais mariée à un homme, mais à Dieu. Que tous ces éléments se rattachent à la peur panique de la sexualité manifestée d'emblée par Berte, qui jouera encore un rôle crucial dans le dénouement puisque Berte, parfaitement heureuse dans son célibat volontaire, ne se décidera à avouer qu'elle est l'épouse de Pépin qu'afin d'éviter les étreintes d'un homme... ce même Pépin qu'elle n'a pas reconnu, cela est parfaitement clair. La formulation du vœu de Berte est très significative : alors que personne en fait n'est à sa recherche, s'engager à dissimuler son identité est une monnaie d'échange acceptable vis-à-vis de Dieu, en échange justement du salut de la jeune femme qui se croit aux portes de la mort. Mais la précision introduite par Berte dans le texte de son serment suggère une hiérarchie des valeurs un peu différente, et que ce n'est pas un si grand sacrifice que de renoncer à son statut d'épouse :

[...] ja mais ne dirai, tant com porrai durer, Que soie fille a roi ne k'a Pepin le ber Soie femme espousee $[\ldots]$.

\footnotetext{
${ }^{18}$ Une variation sur ce motif est celle du quasi fabliau d'Alibech et Rustico, où la jeune fille désireuse d'accéder à la sainteté reçoit au contraire un enseignement bien différent de la part de l'ermite qui l'accueille dans sa cellule... avant, éventuellement, de la renvoyer dans le monde où elle est toute surprise de découvrir que les joies du mariage n'ont rien à envier à celles du couvent : voir Boccace, Décaméron, $3^{\mathrm{e}}$ journée, nouvelle 10.

${ }^{19}$ Voir Jean Renart, L'Escoufle, éd. F. Sweetser, Genève, Droz "TLF", 1974. L'héroïne, Aelis, est amenée à demander incognito l'hospitalité à une jeune fille et sa vieille mère, puis vit pendant deux années du travail de broderie qu'elle et son amie Isabel accomplissent pour diverses grandes dames.
} 


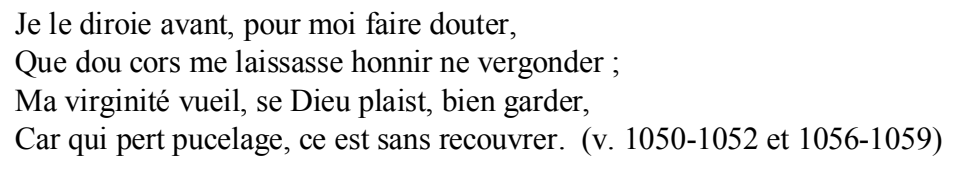

Le sentiment est louable, et fort chrétien, mais un peu surprenant dans la bouche d'une femme de roi dont le rôle est clairement défini comme celui de la future mère d'un héritier royal. On a l'impression que deux modèles narratifs incompatibles, celui - pour dire vite - du roman lignager, et celui de la «vie de sainte» se télescopent dans la figure de Berte, dont le chagrin à la perspective de ses noces royales prend rétrospectivement une coloration différente, surtout lorsqu'on lit la prière qui clôt cette partie du récit:

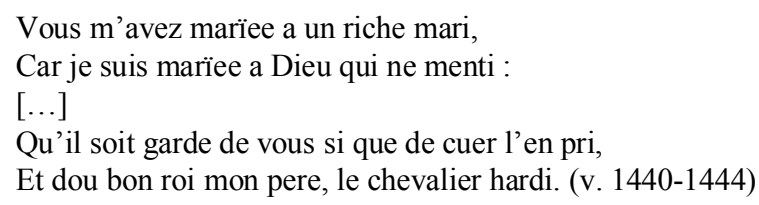

Ce que veut dire Berte, bien sûr, c'est que la reine Blancheflour serait bien surprise, et bouleversée, de savoir que sa fille, trahie par la "serve», a dû renoncer à son royal époux et s'en remettre à Dieu. Cependant, le concept de «mariage divin » s'applique ordinairement aux nonnes, et plus précisément aux saintes, et il faut faire abstraction du sens obvie des vers pour s'en tenir à leur signification sarcastique. En outre, l'époux humain, le roi Pépin, brille par son absence dans les intentions de prière de Berte : elle recommande bien à Dieu un roi, bon chevalier hardi, mais il s'agit de son père, conjoint à sa mère dans l'esprit de la jeune femme. Elle renonce à Pépin et à son rang dans la société avec une légèreté qui n'est pas entièrement louable d'un point de vue médiéval ; enfin, d'un point de vue narratif et générique, cette renonciation de la part de l'héroïne détourne le texte en train de s'écrire de l'épopée, ou du récit lignager, vers le roman d'aventures ou la vie de sainte.

Berte étant en quelque sorte « mise sur la touche », l'attention du narrateur est reportée sur ce qui devrait être, après tout, la scène centrale de l'aventure : la cour de France, où règne l'usurpatrice. Il semble toutefois qu'il n'y ait pas grand-chose à en dire : la «serve» se montre d'une rapacité indigne de ses origines nobles supposées, elle amasse un grand trésor au lieu de faire preuve de «largesse» et se fait conséquemment haïr par son peuple. Ses fils, brillante illustration de l'adage « mauvais sang ne saurait mentir», marchent sur ses traces... et personne ne semble trouver vraiment à redire à la situation. De manière analogue, des changements considérables interviennent à la cour de Hongrie, la sœur et le frère de Berte meurent tous deux « dans les quatorze mois » qui suivent le mariage - mais en dépit d'une timide tentative du roi Floire pour «adopter» l'un de ses petits-fils présumés pour le trône de Hongrie, le statu quo n'est pas remis en question. « [P]rès d'uit ans et demi » (v. 1885) s'écoulent avant que la reine Blancheflour, à la suite d'un rêve qu'on ne peut guère qualifier de «prémonitoire», ne demande au roi son époux de l'autoriser à rendre visite à leur seule enfant survivante, qu'ils aiment tous deux plus que tout au monde, mais dont ils ne semblent guère s'être souciés pendant les huit 
années en question ${ }^{20}$. Le voyage de la reine de Hongrie, et surtout son accueil à Paris par le roi Pépin, sont essentiellement surprenants par la précision des détails et l'insistance sur la sollicitude du souverain à l'égard de sa belle-mère; quand Blancheflour contemple la cité de Paris et se réjouit de savoir sa fille si bien mariée, Pépin «l'adestre, forment l'a honnoree » (v. 1976), alors même qu'on ne l'a jamais vu dans une telle attitude vis-à-vis de Berte ${ }^{21}$. Quant au coup de théâtre que devrait constituer la scène de « reconnaissance » entre la mère et celle qui n'est pas sa fille, elle est pratiquement escamotée, et ne peut faire sens que si le lecteur connaît la légende de «Berte as grans piés », dont jusqu'à présent le texte d'Adenet n'a pas dit un mot.

Tout au long de cet épisode, les traîtres ne font pas preuve d'une vilenie très endurcie: quand elle apprend la venue de la reine de Hongrie, la «serve»n'a qu'une idée, c'est de s'enfuir avec ses fils et son trésor. C'est la vieille Margiste qui lui ordonne de jouer la malade, ce qui, à moins de supposer des projets assassins (sur la personne de sa propre fille, ou sur celle de Blancheflour?), ne pourrait jamais que retarder l'échéance. En définitive, après s'être d'abord laissé interdire la chambre royale, Blancheflour soupçonne la supercherie au prétexte que jamais sa fille ne refuserait de la voir et de lui faire fête, même à l'article de la mort, et se précipitant dans la pièce arrache les couvertures :

Si la sacha que toute la serve descouvri :

Blancheflour voit les piez, tous li cuers li failli. (v. 2149-2150)

Encore faudrait-il que le lecteur comprenne de quoi il est question... Or, dans les portraits, ou plus exactement, les rapides mentions de la beauté de Berte qui émaillent le texte, il est question de sa peau «blanche et vermeille» et de ses tresses «qui estoient molt blondes »"22, mais rien n'est dit à propos de ses pieds. De surcroît, ce motif n'est pas repris par la suite : Blancheflour, folle de douleur, réclame sa fille à Pépin, et celui-ci comprend tout de suite, a posteriori, ce qui s'est passé le matin après ses noces - mais ni l'une ni l'autre n'éprouvent le besoin de mentionner le signe de reconnaissance infaillible que constitue pourtant, d'après les récits traditionnels, le «grant pié », ou pied de canard, de Berte.

Tout se passe au contraire comme si l'ensemble de la séquence s'efforçait d'occulter complètement un « détail » crucial, qui a l'inconvénient de tirer la future mère de Charlemagne du côté du surnaturel, ou à tout le moins de lui infliger un « défaut », une déformation physique qui ne peut que nuire à l'aura de perfection qui

${ }^{20}$ Le texte, comme il convient, ne manque pas d'insister sur le principe de rétribution divine, qui ne saurait manquer de punir les méchants et de récompenser les bons : «Bien avez oÿ dire mainte fois et retraire / Que traÿson et murdre couvient k'en la fin paire» (v. 1684-1685). Néanmoins, les variations un peu maladroites sur ce thème suggèrent un certain malaise vis-àvis de l'argument, censé appuyer un récit de «justice immanente » qui se fait un peu attendre.

${ }^{21}$ Dans le même mouvement, d'ailleurs, Blancheflour insiste sur le très grand amour que Floire porte à sa fille Berte : "Car il aime sa fille plus que riens qui soit nee» (v. 1981), ce qui réactive curieusement (dans la bouche de la mère et épouse des protagonistes) les connotations incestueuses esquissées lors des adieux du roi de Hongrie et de Berte.

${ }^{22} \mathrm{C}$ 'est au point que le qualificatif de «blonde » appartient à l'hémistiche formulaire employé pour qualifier Berte, y compris dans la forêt : «la blonde, l'eschevie » (v. 2165, par exemple). 
doit environner l'empereur ${ }^{23}$. La légende du pied de cane rattache en effet Berte à ces figures féminines ambiguës qui participent d'une double nature humaine et animale, fées-oiseaux ou fées-« serpentes », dont il ne fait plus bon se réclamer au $\mathrm{XIII}^{\mathrm{e}}$ siècle: au XII ${ }^{\mathrm{e}}$ siècle, un Richard Cœur-de-Lion peut bien se vanter d'avoir pour ancêtre une «démone" s'envolant de l'église sous sa forme de dragon, et au $\mathrm{XIV}^{\mathrm{e}}$ siècle la famille de Lusignan peut se glorifier de faire remonter ses origines à Mélusine. Mais au temps d'Adenet, et tout particulièrement dans la perspective d'une écriture «réaliste» ou dans le cadre d'un texte à vocation semi-religieuse, ce genre de détails ne "passe» plus. Une Berte «féerique» forcerait la crédulité et ferait basculer le texte du côté du merveilleux, ou jetterait le discrédit sur l'orthodoxie du genre épique en général, et de ce volume d' «enfances» («préenfances », peut-être ?) de Charlemagne. Ainsi peut donc s'expliquer la suppression du détail révélateur - mais du même coup, l'histoire, sans vouloir faire de jeu de mots, devient boiteuse, puisque la seule information de nature «littéraire» concernant la mère de Charlemagne est cette histoire de «pied» particulier qui lui permet d'être identifiée, et qui partant justifie tout le scénario de la fiancée substituée.

$\mathrm{Si}$ on se réfère aux contes traditionnels de ce type, on comprend mieux pourquoi Adenet se trouve en quelque sorte contraint de faire du remplissage et de substituer, à son tour, des éléments allogènes à son schéma narratif de base afin de produire, non un «récit des origines» fondé sur un topos merveilleux, mais une pseudo-chanson de geste édifiante. D’une manière analogue, le sort réservé aux trois «traîtres» oscille entre le modèle «merveilleux», qui voudrait l'exécution immédiate, et sans fioritures, d'Aliste, Margiste et Tibert, et un modèle « épicoréaliste ", qui d'une part substitue au bûcher l'écartèlement à quatre chevaux pour Tibert, dans la tradition de la mise à mort de Ganelon, et d'autre part doit tenir compte du fait que la «serve», ayant eu des enfants du roi, ne peut simplement être exécutée. Alise et ses enfants sont enfermés dans un couvent, ce qui constitue d'autant moins une punition appropriée que l'usurpatrice est autorisée à emporter son trésor, qui est apparemment la seule chose qui l'intéresse. Margiste, l'âme du complot, est mise à mort ; et Tibert reçoit le châtiment «normal » des traîtres de chansons de geste, mais seulement après avoir, spontanément, révélé au roi qu'il n'a pas tué Berte - non par bonté, mais parce que Moran l'en a empêché. D'ailleurs, ajoute-t-il, Berte est sans doute morte quand même, elle a dû périr tout de suite après son abandon dans la forêt.

Huit ans et demi ont passé, ne l'oublions pas. En dépit du pronostic pessimiste (mais très réaliste) de Tibert, le roi Pépin envoie partout des messagers à la recherche de l'épouse pour laquelle il se découvre soudain un amour ardent. Inversement, la reine Blanchefleur, qui est venue de si loin pour revoir sa fille, s'en retourne en Hongrie sans même attendre les résultats de cette quête improvisée, et tout son royaume partage sa douleur d'avoir «perdu» Berte. Pendant ce temps, Symon et Constance ont des soupçons lorsqu'ils entendent parler de la jeune reine

\footnotetext{
${ }^{23}$ Dont la sainteté, à l'époque probable où Adenet compose Berte (c. 1272-1273), ne fait plus le moindre doute, la canonisation ayant eu lieu en 1166 - mais peut-être est-elle récemment redevenue un sujet d'actualité, si l'on admet que la Legenda aurea de Jacopo da Varazze commence à circuler dans les années 1260-1270.
} 
perdue en forêt, et ils interrogent Berte. Mais celle-ci, terrifiée à l'idée de trahir son vœu, affirme qu'elle n'est pas la reine :

Symon, fait ele, sire, pour quoi vous celeroie,

Se j'estoie roÿne? Grant folie feroie.

[...] bien dervee seroie,

Se j'estoie roÿne et puis le vous celoie.

Ce ne seroit pas sens, se je m'en escusoie,

Ains seroie molt fole, se de ce vous mentoie. (v. 2512-2513 et 2516-2519)

«Molt fole », en effet; et pourtant, c'est précisément ce qu'elle fait, sans que le texte fournisse le moindre embryon de justification à ce comportement absurde. À chaque étape de cette séquence, les attentes du lecteur sont déçues: aucune des pistes narratives qui semblent s'ouvrir ne mène nulle part, et lorsque Pépin déclare de manière catégorique qu'il refuse de se remarier, alors même que Berte refuse tout aussi catégoriquement de faire valoir son identité, le récit paraît acculé à une impasse.

Il faut, pour ainsi dire, repartir à nouveaux frais, en faisant appel à un autre topos des romans d'aventure: celui de la chasse fabuleuse, qui conduit ordinairement le héros à la fée-amante. Ici, mutatis mutandis, le "veuf inconsolable » qu'est Pépin décide le jeudi d'aller chasser un «grant cerf», alors que le dimanche précédent il était en proie au désespoir d'avoir perdu sa femme :

Quant li rois l'a veü, forment li abeli ;

Sor un bon chaceour si le cerf poursivi

Que trestoutes ses gens uns et autres perdi. (v. 2620-2622)

Puis, dès qu'il a rencontré selon les usages la créature féerique qui lui est destinée dans le cadre d'une pseudo chanson de geste à tendances hagiographiques, il s'agit d'une jeune fille qui prie à la chapelle pour le roi de France -, ce même roi qui a juré de ne pas se remarier se comporte comme n'importe quel chevalier de pastourelle ou de lai breton, et «prie d'amour » la demoiselle :

Quant Pepins voit son ris vermeil et rouvelent,

Qu'ele ert blanche et vermeille et de joene jouvent,

D'amour et de desir tous li cuers li esprent. (v. 2668-2670)

Version «modernisée »: il lui offre (sans révéler son véritable nom, bien sûr) de faire d'elle sa concubine, et la presse de si près que la malheureuse Berte n'a d'autre solution que de révéler son identité :

Sire, fait ele au roy, je vous vueil commander

$[\ldots]$

K'a la fenme Pepin ne puissiez adeser :

Fille sui le roy Floire, de ce n'estuet douter,

Et fille Blancheflour, que Dieus puist honnorer. (v. 2729 et 2732-2734) 
On peut, soit dit en passant, se demander ce qu'aurait donné la variante selon laquelle le roi se serait servi de son titre pour impressionner la jeune fille: Berte se serait alors trouvée dans le type de dilemme qui conduit à la mort des héros comme Cuchûlainn, forcés de contrevenir à l'une ou l'autre des geasa qui pèsent sur eux ${ }^{24}$ ! Quoi qu'il en soit, à peine a-t-elle concédé sa défaite qu'elle se reprend et affirme avoir menti pour préserver sa virginité ; le roi pourtant n'est pas convaincu, comme il le dit à Symon, car la jeune femme lui rappelle de manière frappante sa "fausse " épouse, la «serve» Aliste, sauf qu'elle est encore plus belle - ce qui, bien sûr, fait écho au commentaire un peu bizarre de Blancheflour à propos de la ressemblance entre les deux jeunes filles. Alors que Symon «devine » que les mensonges de Berte proviennent d'un « vœu» qu'elle a voué au cours de son expérience traumatisante, Pépin décide d'envoyer chercher les souverains de Hongrie, seuls habilités à reconnaître leur fille.

Là encore, les attentes du lecteur sont systématiquement déçues : le récit relate avec une grande précision les étapes qui vont permettre la scène de reconnaissance finale, depuis la lettre que Pépin fait écrire à son chapelain jusqu'aux détails du voyage de Floire et Blancheflour vers Paris, puis vers Le Mans, en passant par leurs angoisses et leurs espoirs, et le dialogue qu'ils ont avec Pépin, puis avec Symon. Mais la scène de reconnaissance elle-même est non seulement très brève, mais complètement «anodinisée»: alors qu'une nouvelle fois il s'agit pour Blancheflour d'entrer dans une chambre où se trouve peut-être sa fille, toute allusion au signe qui permet d'identifier Berte à coup sûr est éliminé. Le seul "pié» présent dans la laisse CXXVI est celui de Blancheflour :

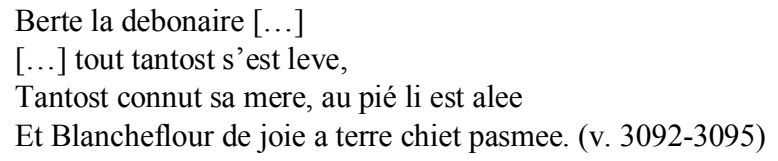

En revanche, la tendresse entre le père et la fille est une nouvelle fois soulignée, en des termes qui seraient plus appropriés pour décrire les retrouvailles d'un couple amoureux :

Rois Floires prent Bertain que tant ot desiree,

Doucement l'a baisie, estrainte et acolee. (v. 3099-3100)2.5

Ce vocabulaire est, comme de bien entendu, totalement absent de la rencontre entre Pépin et Berte; tout au plus celle-ci, qui «s'esmervelle molt» que l'homme qui l'a contrainte à briser son vœu soit en fait son mari, juge-t-elle à propos de remercier le ciel - «s'il en est bien ainsi », dit-elle avec un manque d'enthousiasme marqué. Évitons de demander, dans un texte où la question de la ressemblance et de

\footnotetext{
${ }^{24}$ Dans le cas de Cuchûlainn, le « chien de Chulain », qui ne doit jamais manger de viande de chien, mais jamais non plus de refuser de prendre part à un repas quand on l'y invite, le dilemme se pose lorsque des sorcières l'invitent à partager leur dîner... de viande de chien. Cuchûlainn sait alors que sa mort est proche, et inévitable, quel que soit son choix.

${ }^{25}$ Ajoutons à cela le vers un peu étrange qui suit immédiatement : "Blancheflour se relieve, des mains li a ostee...» (v. 3101).
} 
l'apparence sont cruciales, comment il se fait que la jeune épousée ne reconnaisse pas le mari dont on l'a arrachée 8 ans et demi plus tôt, qui lui-même se souvient d'elle seulement en fonction de sa ressemblance avec l'usurpatrice...

Il n'y a, semble-t-il, plus grand-chose à ajouter. Pourtant, l'œuvre ne s'achève pas avant près de 350 vers - pour un texte qui en compte au total 3486 , ce n'est pas négligeable - divisés en 17 laisses. Cette cauda se préoccupe essentiellement de distribuer les récompenses qu'ils méritent aux personnages positifs que sont Moran et Symon et sa famille. Elle prend soin aussi de raccompagner Floire et Blancheflour en Hongrie, et de résoudre la question de la passation du royaume: contrairement à ce que l'on pourrait penser, après l'insistance du texte sur le motif de l'adoption, par les souverains hongrois, d'un de leurs petits-fils, il n'est pas question, par exemple, de faire de Gille, sœur aînée de Charlemagne, l'héritière de la Hongrie - pas question non plus de «rajouter » au lignage carolingien officiel un frère supplémentaire qui pourrait prendre en charge ce royaume. Ce sont Floire et Blancheflour eux-mêmes qui, de retour chez eux, conçoivent une nouvelle fille, qu'ils baptisent Constance en l'honneur de la femme de Symon, qui a si bien pris soin de Berte. Cette naissance tardive - quel âge peut avoir Blancheflour? - n'est pas sans rappeler celle du petit Godin dans les Continuations d'Huon de Bordeaux, où Esclarmonde, très «jeune arrière-grandmère », selon l'expression de Caroline Cazanave, démontre son appartenance à la Féerie en concevant un enfant en dehors des lois naturelles ${ }^{26}$. Elle clôt en tout cas l' « incidente » hongroise, et permet au narrateur de se focaliser sur son couple royal enfin réuni, sinon en proie au bonheur le plus parfait; Floire, Blancheflour, Pépin, les seconds rôles et le peuple de France peuvent bien être dans l'allégresse, la dernière mention de Berte, quasiment, la présente une nouvelle fois dans les larmes et le deuil :

Si dirai de Pepin $[\ldots]$

Et de Berte cui Dieus doinst bone destinee,

Qui pour pere et pour mere remest molt esploree. (v. 3456-3458)

Enfin, la laisse CXLIV introduit le personnage essentiel dont toute l'œuvre est censée préparer l'avènement: Charlemagne; mais pour la dernière fois, la formulation ressortit à une stratégie déceptive : «[li] premiers des enfans » de Pépin et de Berte n'est pas Charlemagne, ce n'est même pas un hoir mâle - et le malentendu s'accroît si l'on considère que la laisse précédente parlait également d'enfants, les deux fils de la «serve», dont elle annonçait la néfaste carrière. Celle de Charlemagne, au demeurant, laisse-t-elle réellement à envier à celle de ses demifrères? Certes, une belle période anaphorique riche en expressions formulaires typiques des chansons de geste vient clôturer le poème :

Par lui fu la loys Dieu levee et essaucie,

Par lui fu mainte terre de paiens essillie,

Maint hiaume descoupé, mainte targe percie,

${ }^{26}$ Voir C. Cazanave, D'Esclarmonde à Croissant. Huon de Bordeaux, l'épique médiéval et l'esprit de suite, Université de Franche-Comté, 2008, en particulier les pages 34-52. 
Maint hauberc desrompu, mainte teste trenchi ;

Molt guerroia de cuer sor la gent paiennie... (v. 3481-3485)

Mais le dernier vers constitue un brutal anti-climax :

Si k'encore s'en duelent cil de cele lignie. (v. 3486)

Il s'agit de « la gent paiennie », qui ont en effet à se plaindre de la prouesse guerrière de Charlemagne - et tout ce qui afflige les païens doit réjouir les chrétiens. Néanmoins, l'impression finale est celle de l'affliction, du deuil qui frappe une «lignée» dont il faut un effort d'imagination grammaticale pour se rappeler qu'elle se rapporte aux nations païennes, alors qu'on vient de passer près de 3500 vers à préparer la naissance du héros qui constitue le point culminant d'une autre lignée, essentielle pour les chansons de geste : celle des Carolingiens.

Il serait facile de mettre ces indices de dysfonctionnement et ces cahots de la narration au compte de l'inexpérience de l'auteur : "Bertain », dans la liste de ses œuvres que fournit obligeamment Adenet dans le prologue de son Cleomadés, figure parmi les premiers titres ${ }^{27}$. On aurait donc affaire à un galop d'essai, un texte où l'écrivain ne maîtrise pas encore complètement ses effets. Cependant, cette interprétation fait bon marché de l'habileté avec laquelle les hoquets de la fiction sont orchestrés dans Berte as grans piés. On n'est pas en présence d'un texte imparfait, mineur, «de jeunesse »; on est confronté à un ouvrage dont l'ambiguïté est une part essentielle, et dont les constants non sequitur au niveau de l'intrigue comme de l'interaction des personnages signalent un malaise plus fondamental. Génériquement, Berte ne rentre dans aucune catégorie préétablie: ni roman ni chanson de geste, ni fabliau ni vie de sainte, elle constitue plutôt un patchwork d'éléments formels ou structurels empruntés à chacun de ces genres. Il en va de même sur le plan de la «senefiance»: l' «aventure» de Berte et de Pépin, ou de Berte seulement, se situe de toute façon en marge. Ni tout à fait dans le droit fil de la « matière de France », ni même assimilable aux « enfances » de héros qui complètent les cycles par des «chansons» de tonalité moins guerrière que les premières chansons de geste, elle ne peut non plus être traitée comme pur matériau romanesque - il s'agit, après tout, de l'«estoire», véridique, de la mère de Charlemagne. Coincé entre un substrat légendaire en quelque sorte inapproprié, et fragmentaire en sus, et une doxa chrétienne peu favorable à l'élaboration romanesque, Adenet construit un texte qui reflète à tous les niveaux la nature hybride et ambiguë de son sujet. Berte as grans piés n'est pas une chanson de geste manquée, ni un roman épico-hagiographique : c'est une œuvre inclassable dont les failles et les manques signalent la différence - une «conjointure » dont précisément

${ }^{27}$ Voir A. Henry, Les CEuvres d'Adenet le Roi. Tome V. Cleomadés, Bruxelles, Presses universitaires de Bruxelles, 1971 : «Je qui fis d'Ogier le Danois / Et de Bertain qui fu ou bois / Et de Buevon de Commarchis / Ai un autre livre rempris, / Mout merveilleus et mout divers » (v. 5-9). Notons que même dans le cas de Cleomadés, que tout le monde considère comme un roman sans se poser de questions génériques à son sujet, Adenet emploie le vocable général «livre », et insiste sur la « diversité » de cette œuvre. 
le propos est de mettre en scène, ou en écrit, la dis-jointure que représente «Berte au bois ».

Anne Berthelot

University of Connecticut, Storrs, USA 



\title{
酶RM
}

\section{Adenet le Roi entre chanson de geste et roman : les vers d'intonation dans Berte as grans piés}

\begin{abstract}
Résumé : A. Henry a vu dans les quatre ouvres d'Adenet le Roi une évolution du genre épique vers le genre romanesque. Berte as grans piés, qu'il place chronologiquement en troisième position, aurait permis à son auteur de se «libér[er] de l'ancienne épopée ». Il n'en reste pas moins que Berte adopte la forme épique : jusqu'à quel point?

À travers l'analyse de l'emploi des vers d'intonation, marqueurs de la laisse épique strictement définis et classés par plusieurs critiques, il s'agit de mieux comprendre le projet de l'auteur: l'étude révèle qu'Adenet non seulement maîtrise et exploite toutes les caractéristiques structurelles et sémantiques des vers d'intonation, mais de plus leur apporte les mêmes adaptations que ses contemporains. S'insérant dans un moule rigoureusement pensé, les innovations thématiques témoignent dès lors plus de l'évolution de la chanson de geste au XIII siècle chez les créateurs que de son abâtardissement chez de maladroits épigones.
\end{abstract}

Abstract: A. Henry saw in the four works of Adenet le Roi an evolution from the epic to the novel. He claimed that Berte as grans piés, which he chronologically put in third position, allowed its author to "free himself from the old epic." It is nevertheless a fact that Berte adopts the epic form. One may well ask, then, to what extent it does so.

Thanks to an analysis of the use of intonation verses, those markers of the epic stanza strictly defined and classified by several critics, our aim is to get a better understanding of the author's project. Indeed, our survey reveals that Adenet not only mastered and made use of all the structural and semantic characteristics of intonation verses, but also that he introduced the same adjustments as his contemporaries. Thus, complying with the rules of a rigorously thought-out form, his thematic innovations show the evolution of the French epic in the $13^{\text {th }}$ century among creators rather than its degeneracy among clumsy epigones.
Je qui fis d'Ogier le Danois et de Bertain qui fu ou bois et de Buevon de Conmarchis ai un autre livre rempris, mout merveilleus et mout divers.

Ces vers du prologue de Cleomadés ${ }^{1}$ semblent offrir une chronologie cohérente des œuvres d'Adenet: bien que la datation de Buevon de Conmarchis pose problème, notamment en raison de sa médiocrité ${ }^{2}$, les critiques s'accordent globalement sur la place accordée aux trois autres textes, place qui offre l'avantage

\footnotetext{
${ }^{1}$ A. Henry, Les Euvres d'Adenet le Roi, t. 5, Cleomadés, Bruxelles, 1971, v. 5-9.

${ }^{2}$ Voir A. Henry, introduction à l'édition de Berte as grans piés (Genève, Droz, 1982), p. 25 -

26. C'est l'édition que nous utiliserons ici.
}

Cahiers de Recherches Médiévales, 18, 2009 
de présenter une évolution littéraire claire, qui mène de la chanson de geste ${ }^{3}$ au roman. Selon Albert Henry, Adenet «se montre de plus en plus romancier » au fil de la récriture des Enfances Ogier, il devient «romancier totalement libéré de l'ancienne épopée », «cède entièrement à son inclination » dans Berte as grans piés, pour finir «en plein roman courtois» dans le Cleomadés, où «l'évolution est accomplie $»^{4}$.

L'histoire d'Adenet écrivain serait donc celle d'un homme qui aurait progressivement trouvé sa voie / sa voix, dans un parcours rectiligne - qui ne laisse pas cependant de paraître suspect au critique contemporain, étant donné la labilité des notions de genre appliquées à la littérature médiévale. Cette question du genre n'en constitue pas moins un angle d'approche intéressant de l'œuvre: si l'on se fonde sur la forme (critère moins discutable que les thèmes ou les personnages) choisie, Adenet s'est inscrit trois fois dans le moule de la chanson de geste (puisque seul Cleomadés est écrit en octosyllabes à rimes plates), et si la forme de Buevon et d'Ogier a assurément été dictée par le modèle auquel il a eu recours (le Siège de Barbastre pour Buevon, une des versions des Enfances Ogier pour sa propre version du même récit) et par le thème du récit, le doute est permis pour Berte, dont la légende circulait sous des formes diverses ${ }^{5}$. Trois fois sur quatre donc, y compris pour deux œuvres qui ne sont pas présentées comme étant de commande (Buevon et Berte), Adenet choisit la forme épique - alors qu'on s'accorde à lire dans son œuvre un irrésistible attrait pour le romanesque : qui l'y oblige donc ? Certes, Berte est, à l'époque où il écrit, d'abord connue comme la mère de Charlemagne, et en ce sens elle est a priori un personnage de la geste du roi ${ }^{6}$, mais son histoire, contrairement à celle d'autres femmes liées à l'épopée ${ }^{7}$, ne contient aucun épisode proprement "épique $»^{8}$. Le texte (qu'Adenet nomme de préférence " estoire $»^{9}$ ), par le possible écart entre sa forme et son thème, et sa position chronologiquement intermédiaire

\footnotetext{
${ }^{3}$ Idéalement, Buevon, remaniement donc «maladroit» (A. Henry) de chanson de geste, prendrait place en tête de cette liste. Notons tout de même qu'il n'est pas sûr qu'Ogier ait précédé Berte.

${ }_{4}$ Voir Albert Henry, op. cit. et notice «Adenet le Roi» du Dictionnaire des Lettres Françaises. Le Moyen Age (Paris, Fayard, 1994), p. 19.

${ }^{5} \mathrm{R}$. Colliot pense que Berte aurait eu une source en alexandrins (Adenet le Roi, "Berte aus grans pies ». Étude littéraire générale, Paris, Picard, 1970, 2 vol., p. 287). Quoi qu'il en soit, en adoptant les laisses dérivatives ( « une laisse monorime masculine [est suivie de la] laisse sur la rime féminine correspondante », A. Henry, introduction à l'éd. cit., p. 41-42), Adenet a forcément mené un travail personnel important.

${ }^{6}$ Bien qu'aucun fait historique ne donne son assise au texte.

${ }^{7}$ Florence de Rome, par exemple, également datée du XIII ${ }^{\mathrm{e}}$ siècle.

${ }^{8} \mathrm{La}$ critique au demeurant a souvent préféré étudier les éléments «romanesques» ou folkloriques du texte. Voir cependant R. Colliot, op. cit. (la question des vers d'intonation est brièvement abordée p. 186-188 et la forme p. 274 à 291), qui conclut néanmoins sur les «qualités $\mathrm{d}[\mathrm{e}]$ romancier classique» d'Adenet (p. 318). Elle cite également un ouvrage ancien: A. Bovy, Adenet le Roi et son ouvre. Étude littéraire et linguistique, Bruxelles, 1898. Nous n'avons pu consulter cet ouvrage, qui semble sévère à l'égard d'Adenet. Signalons enfin qu'il existe quelques articles portant sur les prières de Berte.

9 À propos de son propre texte (plutôt que de la légende qu'il rapporte) : «estoire [...] rimee » (v. 20), « estoire » (v. 23 et 899$)$.
} 
dans l'ensemble de l'œuvre ${ }^{10}$, se prêtait donc à une nouvelle étude "générique » de l'écriture d'Adenet : à cet égard, le choix de la laisse, avec les fortes contraintes qu'elle implique ${ }^{11}$, était intriguant et fournissait un outil possible de mesure de "l'épicité » du texte pour un auteur si souvent appelé romancier. Notre étude s'attachera aux vers d'intonation, qui offrent plusieurs angles d'approche de l'écriture épique : leur stéréotypie, leur relation aux autres parties du texte, et enfin les thématiques par lesquelles ils ouvrent une laisse.

Dans la mesure où la chanson de geste se définit d'abord formellement par la récurrence, plusieurs critiques ${ }^{12}$ ont proposé des systèmes de classement des vers d'intonation. Ceux-ci mettent en avant, en les organisant parfois de manière un peu différente, un petit nombre de préférences formelles à l'ouverture d'une laisse. Bien que ces structures de vers puissent également se trouver dans le corps de la laisse, sont privilégiés comme vers d'intonation principalement les types suivants :

- le premier hémistiche est occupé par la mention d'un personnage sujet, désigné par un mot plein ou un groupe de mots plutôt que par un pronom ou une désinence verbale.

- le vers débute par une inversion ${ }^{13}$. Dans l'inversion considérée comme proprement épique ${ }^{14}$, le vers commence par un verbe, voire par un attribut du sujet suivi du verbe estre ${ }^{15}$. La pratique de l'inversion permet d'élargir le type à plusieurs autres constructions : ouverture du vers par un démonstratif, un adverbe (notamment or, mais aussi molt), un complément (d'objet, circonstanciel).

- le vers commence par la conjonction quant (sans inversion).

- le vers commence par une apostrophe (du narrateur à son public ou d'un personnage à un autre).

\footnotetext{
${ }^{10}$ Bien que les Enfances Ogier témoignent déjà de la mixité de l'œuvre (à ce sujet, voir V. Méot-Bourquin, "Les Enfances Ogier ou la chanson de geste entre tradition épique et conception courtoise », L'Épique : fins et confins, éd. P. Frantz, Presses universitaires FrancComtoises, 2000, p. 127-154), et E. Hoyer-Poulain, «Tradition / Trahison ? Scènes de bataille dans les Enfances Ogier d'Adenet le Roi », Plaist vos ör bone cançon vallant? Mélanges François Suard, Université Charles-de-Gaulle-Lille 3, 1999, t. 1, p. 435-444), les thèmes abordés affichent d'emblée une évolution : l'on passe, avec Ogier, du moment essentiel de la mise à l'épreuve du jeune guerrier à, avec Berte, l'histoire d'une « innocente persécutée ».

${ }^{11}$ Bien qu'Adenet se plaise manifestement à la contrainte, puisqu'il se vante de l'originalité de son écriture et du choix des laisses dérivatives.

${ }^{12}$ E. A. Heinemann résume ces différents classements (Pope, Rychner, Gittleman, Subrenat, Wathelet-Willem, Baroin, Lachet, Boutet) avant de proposer le sien dans L'Art métrique de la chanson de geste, essai sur la musicalité du récit, Genève, Droz, 1993, p. 181 et suivantes. Nous avançons ici une synthèse.

${ }^{13}$ D. Boutet: «la forme la plus épique est l'inversion» (Jehan de Lanson, technique et esthétique de la chanson de geste au XIII ${ }^{e}$ siècle, Paris, PENS, 1988, p. 30).

${ }^{14}$ Voir J. Rychner, La Chanson de geste, essai sur l'art épique des jongleurs, Genève, Droz, 1955 , p. 72.

${ }^{15}$ E. A. Heinemann s'interroge sur cette désignation d'«inversion épique » (op. cit., p. 191, note 16) et classe cette construction parmi les cas d'inversion (p. 192).
} 
C. Lachet ${ }^{16}$ propose un classement portant sur le contenu des vers, mais les six catégories qu'il fait apparaître peuvent se répartir dans les types précédents ${ }^{17}$ nous affinerons la typologie ultérieurement.

Un relevé et un classement des vers d'intonation des 144 laisses de Berte as grans piés montre que presque toutes entrent dans les catégories proposées : trente laisses (environ 23\% de l'ensemble) commencent par un personnage sujet; deux vers proposent une "inversion épique» (attribut + estre + GN sujet; aucun ne s'ouvre par un verbe ${ }^{18}$ ) et 73 comportent une autre inversion (plus de $51 \%$ de l'ensemble, dont 16 s'ouvrant par molt, 8 par or, 5 par grant, 2 par forment, les autres commençant pour la plupart par un complément); 19 vers commencent par «quant» sans postposition du sujet (environ 11\%), 16 vers commencent par une apostrophe (environ 10\%), dont un seulement par une apostrophe au public, et seules quatre intonations offrent une structure atypique. Tout d'abord trois constructions SVC avec un sujet non humain : laisses 49 et 73 ( « Ce fu par un lundi, au chief de la semaine »), puis 1.111 (« Li jours fu biaus et clers, qu'il ne pluet ne ne vente »). Mais dans ces trois cas, la construction (et le contenu identique pour deux des trois exemples) introduit dans le vers suivant le nom du personnage principal :

Ce fu par un lundi, au chief de la semaine,

Que Berte fu trouvee en la forest dou Maine. (1. 49 : intonation en deux vers)

Ce fu par un lundi, au chief de la semaine,

Que Blancheflour la bele, cui Dieus doinst bonne estrainne,

S'en aloit vers Paris qui siet par desus Saine. (1. 73 : intonation en trois vers)

Li jours fu biaus et clers, qu'il ne pluet ne ne vente,

Et Berte fu ou bois delez Pepin dolente. (1. 111)

Or J. Subrenat considère cette tournure ${ }^{19}$ comme un «type $[. .$.$] fondamental dans la$ 'grande épopée' $»^{20}$. Si la dénomination peut prêter à discussion $-\mathrm{D}$. Boutet rappelle que la Chanson de Roland préfère généralement la présenter avec postposition du sujet $^{21}$-, la remarque plaide au moins en faveur de sa fréquence. Le dernier cas, laisse 135, peut être interprété comme une variante un peu plus marquée du schéma :

${ }^{16}$ C. Lachet, «Les vers d'intonation dans la chanson de geste d'Ami et Amile», «Ami et Amile», une chanson de geste de l'amitié, éd. J. Dufournet, Paris, Champion, 1987, p. 93 105.

${ }^{17}$ Voir E. A. Heinemann, op. cit., p. 182, note 6.

${ }^{18}$ L'exemple le plus connu est l'ouverture par la formule dire + sujet (du type «Dist Clarïen », «Dist Oliver »), très fréquent dans la Chanson de Roland et totalement absent ici.

${ }^{19}$ «Intonation en deux vers sans inversion du nom du personnage sujet de l'action [...]. Ce dernier se trouve dans le second vers, car le premier est consacré à un élément descriptif » (J. Subrenat, Étude sur Gaydon, chanson de geste du XIII siècle, Université de Provence, 1974, p. 97).

${ }^{20}$ Ibid., p. 97. J. Subrenat cite dans Gaydon « Li jor esclaire et si reluist el prael / Et li dus Gaydes vit venir le cembel». Les deux exemples qu'il cite dans la Chanson de Roland présentent cependant une inversion («Halt sunt li pui... »).

${ }^{21}$ D. Boutet, op. cit., p. 28. 
Par trestoute les viles ou Berte trepassoit,

La gent encontre li de toutes part venoit.

Enfin, il nous faut souligner qu'Adenet n'a recours que deux fois à l'ouverture de laisse par « $\mathrm{Ci}$ lairons » (1. 59 et 106), fidèle en cela à la tradition qui réserve ce type d' " annonce de changement de matière » à l'intérieur des laisses ${ }^{22}$. Autrement dit, les vers d'intonation de Berte as grans piés ne présentent pas d' «irrégularité » par rapport aux structures dégagées par la critique, à propos de chansons de geste plus anciennes ou au genre clairement affiché.

Certes, bon nombre de phrases des romans en octosyllabes médiévaux empruntent également la structure CVS, qui n'est pas par elle-même épique, de même que l'on ne saurait s'étonner de trouver en tête de phrase et de " paragraphe » le nom du protagoniste de l'action - nous y reviendrons. Cependant rappelons qu'il faut prendre la question «par l'autre bout»: ces constructions peuvent se trouver ailleurs dans les textes, mais on ne peut pas en trouver d'autre en tête de laisse. De ce fait, la récurrence de certaines constructions à l'ouverture fait sens : elle remplit en effet une double fonction dans la chanson de geste. D'une part, le fait que l'on trouve à l'initiale ces constructions - et pas les autres - leur confère une fonction structurelle : ce sont les marqueurs traditionnels du début de laisse à l'oral. Ainsi, les retrouver dans Berte témoigne du sérieux apporté par Adenet à la construction de ses laisses : ses «paragraphes » découpent rigoureusement le texte en unités dont les contours, fidèles aux codes, sont nettement marqués et repérables par un public averti. D'autre part, la récurrence des structures syntaxiques joue un rôle musical caractéristique de la dimension lyrique de la chanson de geste (n'oublions pas que le vers d'intonation est lié à un timbre musical d'intonation, qu'il souligne). Mieux, le retour de structures syntaxiques identiques se double fréquemment du retour de mêmes mots; c'est évident avec l'emploi de la conjonction quant (qui peut se répéter immédiatement, par exemple laisses 91 et 92 , ou scander le texte à intervalles relativement réguliers, comme aux laisses 96, 101, 105, 107) ou avec l'adverbe molt (voir aux laisses 123, 125, 128, 130), ou encore avec le retour du prénom Berte en tête de laisse $(1.8,26,32,33,41,50,119)^{23}$, mais cela apparaît également dans la fréquence de formules identiques à l'initiale (comme nous l'avons déjà vu pour les laisses 49 et 73), notamment dans le cas d'inversions «simples » (c'est-à-dire non typiquement épiques, qui pourraient de fait apparaître dans n'importe quelle partie du texte) : «Cel jour fist molt lait tans...»(1. 20 et 22)

Ici, le caractère peu «typiquement» épique de la phrase (construction CV avec sujet omis) est comme compensé par le retour de celle-ci à peu d'intervalle. De même, l'ouverture par «En la forest» scande les laisses 23, 27 et 35, d'autant plus que le sujet qui suit obéit à un jeu de variations proches :

\footnotetext{
${ }^{22}$ E. A. Heinemann, op. cit., p. 193. Après tout, un auteur moins au fait des traditions et de l'allure épiques eût pu juger logique de commencer un «paragraphe » par une transition...

${ }^{23}$ Le fait de répéter le nom du personnage principal en tête de paragraphe n'est naturellement pas spécifiquement épique, mais dans le cadre de la laisse, associée à un timbre d'intonation, cette répétition fait scansion.
} 
En la forest fu Berte repuse... (1.23)

En la forest fu Berte qui fu... (1. 29)

En la forest dou Mans fu la roÿne Berte... (1. 35)

Et le motif peut encore se retrouver dans des constructions comparables, comme :

Par la forest dou Mans, si qu'il fu ajorné,

S'en va Berte as grans piez, n'i a plus demoré. (1. 44)

En la bele forest ou ot maint haut sapin,

En la maison Symon et Constance au cuer fin,

Fu Berte la roÿne, molt tint le chief enclin. (1. 54)

Ces deux constructions peuvent par ailleurs se rattacher à celle que définit $\mathrm{J}$. Subrenat.

De même, si l'on considère les apostrophes intradiégétiques, au nombre de quatorze, on constate qu'elles ne présentent que sept noms différents. De plus «Sire» y revient quatre fois, et «Bele» y fait écho, musicalement et sémantiquement, à « Berte $»^{24}$. À onze reprises, l'apostrophe est suivie de la formule «ce dist $»^{25}$, et le locuteur est quatre fois Symon, trois fois Constance, d'où les formules récurrentes, souvent à proximité, « ce dist Symons » $(1.116,117,118,124)$ ou « ce dist Constance» $(1.51,53,104)$.

De manière générale, non seulement tous les vers d'intonation du texte entrent donc dans un réseau syntaxique (d'autant plus que certains combinent les différents types : le vers qui ouvre la laisse 112, «Molt fu Berte dolente, la roÿne au vis cler », entre dans le type de l'inversion s'ouvrant par un adverbe, mais présente également le nom développé de la protagoniste dans le premier vers), mais la plupart peuvent de surcroît être intégrés à un réseau sémantique et / ou musical d'écho qui laisse de côté bien peu de vers originaux, ce qui confère une forte unité aux contours de la laisse dans Berte. Certes, on pourra objecter qu'Adenet cède à la paresse en puisant dans un stock restreint de tournures, mais la prédilection qu'il affiche pour la contrainte, ainsi que le soin qu'il apporte à la variation dans la répétition ${ }^{26}$ plaident plutôt en faveur d'un travail raisonné.

\footnotetext{
${ }^{24}$ «Sire » : laisses $113,116,117$ et 124 ; «Bele » (à l'adresse de Berte) : laisses 45 et 51 ; «Berte » : laisses 53 et 118 .

${ }^{25}$ Peu de variantes pour celles qui restent: «ce a dit»(1. 113), «dist» (1. 45). Seule l'ouverture de la laisse 58 se distingue.

${ }^{26}$ Voir à ce sujet la série des vers d'intonation des laisses 23 à 35 : «En la forest fu Berte repuse entre buissons »; «La dame fu el bois, qui durement plora »; " Par le bois va la dame, qui grant paour avoit»; "En la forest fu Berte qui fu gente et adroite»; "La fille Blancheflour, la roÿne au cler vis / Fu dedens la forest, molt fu ses cuers pensis »; " La dame fu ou bois desouz un arbre assise » et «Berte fu enz ou bois assise souz un fo » : c'est ce qui constitue dans notre texte l'exemple le plus net de laisses parallèles (qui incluent traditionnellement une reprise ou une variation du vers d'intonation).
} 
Si le système de récurrences a pu être mis en relief, on peut pourtant encore affiner la caractérisation épique du texte. D. Boutet propose d'étudier les types de vers d'intonation en fonction de leur relation au contexte, en séparant ceux qui s'intègrent au mode reprise / résumé / parallélisme, caractéristique de l'épique, de ceux qui relèvent d'une «poursuite pure et simple de la narration » (p. 24) - ce nouveau classement pouvant être enrichi par les analyses menées par E. A. Heinemann, qui étudie les «traits qui ralentissent le débit narratif» (p. 183). Or les différents procédés de la stase constituent des marqueurs nets de la chanson de geste.

Plusieurs des types de vers d'intonation se prêtent particulièrement à la distinction. Tout d'abord celui qui s'ouvre par le nom d'un personnage, lorsqu'il est développé. E. A. Heinemann rappelle que le substantif à lui seul occupe plus de place qu'un pronom, et que «plus la désignation du personnage sujet est longue, et moins le récit avance» (p. 184), notamment compte tenu de l'exiguïté de l'espace métrique; D. Boutet évoque l'«aspect quelque peu hiératique» (p. 25) de cette présentation. Or on sait que l'épopée en général affectionne l'épithète. Dans Berte, cette amplification apparaît au moins 12 fois sur 30 (si l'on s'en tient aux premiers mots du vers), plus ou moins développée, de «Rois Pepins » (1. 143), « Rois Pepins de France » (1. 78), « La roÿne de France» $(1.136,138)$, « Blancheflour la roÿne» (1. $69,82,85,89)$ à «Berte la debonaire, qui n’ot pensee avere» (1. 4) ou «La fille Blancheflour, la roÿne au cler vis » (1.30) et «Blancheflour la roÿne, ou molt ot de bonté» (1. 80) - on voit qu'ici le nom du personnage occupe tout le vers. Le ralentissement lié à la désignation du personnage peut aussi prendre des formes plus complexes, ainsi à la laisse 69 :

\section{Blanchefour la roÿne fu molt de haut parage}

Et bien creans en Dieu et de tres bon corage.

Ou à la laisse 119 :

Berte fu en la chambre, la gente, l'eschevie.

De plus, il peut aussi être mis en relief dans d'autres types, comme dans les vers construits sur une inversion - par exemple laisse 29:

En la forest fu Berte qui fu gente et adroite.

Ou encore dans les vers s'ouvrant sur quant:

Quant Berte ot pris congié a son pere au cuer vrai... (1. 7)

$\mathrm{Au}$ total, un grand nombre de vers d'intonation dans l'œuvre ont recours au procédé, d'autant plus que plusieurs de ceux du type «Molt fu» («Molt fu Berte courtoise et plaine de franchise », 1. 6) ne s'en distinguent pas vraiment. Or à ce sujet, nous ne pouvons que reprendre les conclusions d'E. A. Heinemann à propos du vers « Li cuens Guillelmes fu molt bons chevaliers » : 
Nous savons tous, et depuis longtemps, que Guillaume fu molt bons chevaliers. Le vers sert surtout de signe d'introduction. Le premier hémistiche, entièrement rempli par le sujet du verbe, est statique. Comme le second hémistiche ne se rapporte que de manière lointaine aux événements particuliers à cette partie du récit, il remet à plus tard l'action du récit, et le vers reste essentiellement statique. ${ }^{27}$

Mais ce ralentissement procède d'un mouvement plus large: si les attaques de laisses qui décrivent un personnage bloquent complètement l'action, le temps d'un vers, et en ce sens sont épiques (l'ouverture n'est pas dynamique, le début du «paragraphe» ne coïncide pas avec le début d'une action), celles qui incluent le personnage dans le mode reprise / résumé / parallélisme rappelé précédemment freinent également la poursuite de la narration. Dans ce domaine, Adenet mêle habilement reprise et poursuite narrative. Si l'on s'en tient aux seuls vers commençant par le nom du personnage, on constate qu'ils se répartissent à peu près également entre mode épique et mode narratif ${ }^{28}$, ce qui témoignerait cette fois en faveur d'un mélange des genres, qui n'a rien de nouveau d'ailleurs à la fin du XIII siècle, puisque $\mathrm{D}$. Boutet relève des pratiques similaires au début du siècle dans Jehan de Lanson" ${ }^{29}$ : ces auteurs d'épopées «tardives» respectent le cadre formel épique, mais sont également conscients de l'importance du rythme de la narration.

Les vers fondés sur une inversion peuvent également être analysés suivant le même principe. À cet égard, il est remarquable qu'Adenet ait complètement abandonné l'inversion qui apparaît comme la plus épique, celle où le verbe seul ouvre le vers, et notamment la construction très fréquente dans la chanson ancienne «dist + sujet » : là encore cependant, il faut voir un signe d'évolution du genre, déjà sensible non seulement dans Jehan de Lanson, mais aussi dans Simon de Pouille et Fierabras $^{30}$. Reste qu'Adenet le Roi a assez souvent recours à la construction proche «molt $+\mathrm{v}+$ sujet », dont l'emploi témoigne cette fois d'une plus grande fidélité à la démarche épique, puisque sur seize occurrences, six sont purement statiques (le personnage est décrit, par exemple laisse 125 : «Molt ot ou roi Pepin sage home et apensé $\left.\rangle^{31}\right)$, huit relèvent de la reprise / résumé et deux seulement de la poursuite de la narration (encore ces deux occurrences se situent-elles en début d'œuvre, 1.14 et 21, pour ensuite laisser la place à des emplois uniquement épiques). De plus, dix vers sur seize se construisent avec le verbe être et trois avec le verbe avoir décrivant un sentiment ou une nature du personnage ${ }^{32}$, et de fait présentent un état plutôt

\footnotetext{
${ }^{27}$ E. A. Heinemann, «La laisse dans le Couronnement de Louis », Charlemagne et l'épopée romane, Actes du VII ${ }^{\mathrm{e}}$ Congrès International de la Société Rencesvals, Paris, 1978, p. 387.

${ }^{28}$ Par exemple ceux qui commencent par «Berte» : les vers d'intonation des laisses 8, 26, 33 et 50 relèvent de la poursuite de narration, alors que ceux des laisses 32, 41 et 119 s'intègrent dans une reprise ou un résumé.

${ }^{29}$ D. Boutet, op. cit., p. 25.

${ }^{30}$ Ibid., p. 27.

${ }^{31}$ Le vers est repris en écho à la laisse 139 : «Molt ot ou roi Pepin tres gentill home et ber ». Notons que R. Colliot, oubliant un moment que ce vers de la laisse 125 est un vers d'intonation, ou cédant à la tentation de considérer l'œuvre comme un roman, juge ce vers «difficile [à] défendre » (op. cit., p. 286).

${ }^{32}$ Voir le vers cité ci-dessus, ou encore le vers d'intonation de la laisse 21, pourtant consacré à une poursuite de la narration, mais s'ouvrant bien sur une constatation: "Molt ot Tybers li
} 
qu'une action, sont statiques plutôt que dynamiques - finalement, seuls deux vers ${ }^{33}$ (laisses 64 et 123) présentent une attaque de laisse «dynamique» mais il s'agit de résumé d'actions menées dans la laisse précédente. Autrement dit, dans tous les cas, le vers d'intonation par «Molt», déjà épique par l'emphase qu'il déploie, relève du «ralenti narratif» caractéristique de l'intonation de chanson de geste.

Le respect de l'allure épique apparaît encore plus grand dans les constructions inversées avec "Or» (or $+\mathrm{v}+$ sujet), certes relativement peu employées, mais exclusivement dans un système de reprise. De plus, si cette fois le verbe être n'apparaît que deux fois, les six autres occurrences sont construites sur le verbe aller («Or s'en va», «Or s'en vont»), tournure à laquelle E. A. Heinemann consacre un paragraphe ${ }^{34}$ et qu'il définit comme traditionnelle en tant que charnière entre les laisses, d'autant plus qu'il s'agit bien de «reprise du départ», c'est-à-dire d'un départ déjà indiqué dans la laisse précédente, et non de nouvelle action. De manière générale, si les autres vers d'intonation fondés sur une inversion sont trop nombreux pour qu'on leur consacre une analyse de détail qui alourdirait encore un ensemble peut-être déjà fastidieux, notons que dans la plupart des cas, il s'agit de vers statiques ${ }^{35}$, très souvent d'ailleurs construits avec le verbe être.

Nous l'avons vu, peu de vers échappent à cette construction avec postposition. Les tournures s'ouvrant par la circonstancielle "Quant» offrent pourtant une alternative ${ }^{36}$ qui mérite qu'on s'y arrête brièvement - même si la nature de la temporelle qu'elle représente, qui implique l'idée d'un bilan, de la saisie d'une action déjà menée, la prédispose à un emploi épique ${ }^{37}$. Ainsi, même dans le cas d'une poursuite de la narration (6 cas sur 18), une partie au moins du vers est consacrée à un résumé de ce qui précède (c'est nous qui soulignons dans les exemples) : tantôt il s'agit des conséquences d'une action amorcée dans la laisse précédente (laisse 120 : «Quant li rois Pepins fu dou manoir esloingniés 》-il était parti laisse 119), tantôt le vers d'intonation évoque les réactions à ce qui a été vu ou entendu $^{38}$ (laisse 88 "Quant Blancheflour la serve ainsi parler oÿ»- la laisse 87 contenait le discours d'Aliste). Dans les autres cas, majoritaires, il s'agit bien d'une reprise / résumé des actions menées dans la laisse précédente, et Adenet utilise correctement l'enchaînement, la reprise avec changement de temps : l'action qui a été menée «au présent » dans la laisse précédente est présentée accomplie, au passé composé, dans la nouvelle laisse ${ }^{39}$.

lerres le cuer tres corroucié ».

${ }^{33}$ Le vers d'intonation de la laisse 34 contient bien le verbe faire, mais il s'agit de décrire les conditions météorologiques («Molt fist cele jornee felon tans et cuivert »).

${ }^{34}$ E. A. Heinemann, op. cit., p. 193-195.

${ }^{35}$ Par exemple 1. 40 («Ens ou bois ert la dame, qui n'ert pas asseür »), 190 («Maltalant ot li rois si que tous en rougist»), 1. 61 («Dolans fu li rois Floires, car molt forment li poise») voir également les vers à inversion déjà cités.

${ }^{36}$ On trouve quelques cas de sujet postposé également dans cette construction, par exemple laisse 101.

${ }^{37}$ Dans Jehan de Lanson, elle n'apparaît «qu'exceptionnellement [...] dans des contextes purement narratifs » (D. Boutet, op. cit., p. 26).

${ }^{38}$ Voir la Chanson de Roland, laisse 88 : «Quant Rollant veit que bataille serat». Voir aussi C. Lachet, art. cit., p. 96-97.

${ }^{39}$ Par exemple laisse 92 : «Quant li rois ot fait prendre et Margiste et Tybert ». 
L'écrasante majorité des vers d'intonation de Berte as grans piés offre donc une connaissance précise et un respect minutieux des caractéristiques des débuts de strophe de chanson de geste ${ }^{40}$, en même temps qu'une inscription dans l'évolution du genre au XIII ${ }^{\mathrm{e}}$ siècle. Non seulement Adenet «sait» que l'ouverture d'une strophe épique implique réitération et ralentissement, mais de plus il est suffisamment au fait de l'écriture épique de son siècle pour s'inscrire dans un "mouvement» qui caractérise l'évolution du genre ${ }^{41}$.

C. Lachet classe les vers d'intonation selon leur contenu. Si on laisse de côté les repères formels qu'il ajoute (repères que nous avons déjà exploités), son classement présente six « contenus » types :

- le schéma psychologique, exprimant un sentiment ou une caractéristique psychologique ;

- le schéma topologique, statique (localisation du personnage) ou dynamique (le personnage agit);

- le schéma chronologique (indication temporelle);

- le schéma déclaratif (discours);

- le schéma narratif (résumé);

- les appels au public.

Il ne s'agit pas pour nous de reprendre l'analyse des laisses de Berte suivant cette grille, dans la mesure où elle a déjà de fait été abordée à l'occasion de l'étude structurelle. Cependant, globalement, la question de l'orientation sémantique que donne le vers d'intonation à la laisse, de la marque qu'il lui imprime du fait de sa mise en valeur, ne fût-ce que musicale, participe bien de la détermination du genre du texte. Nous nous contenterons à cet égard d'étudier d'une part le type de personnage qui se trouve mis en valeur à l'initiale, et d'autre part la nature de l'action évoquée.

Si l'on fait la liste des personnages les plus fréquemment cités, que ce soit en position de sujet ou en position de complément, dans les vers d'intonations des 144 laisses du texte, on trouve à 50 reprises Berte (environ 35\% de l'ensemble), puis à 25 reprises Pépin, et enfin 22 fois Blanchefleur (et donc 97 laisses sur 144 s'ouvrent en évoquant l'un au moins de ces trois personnages). Les trois cas sont intéressants. Tout d'abord Berte, incontestable héroïne de l'œuvre (des laisses 23 à 55, presque tous les vers d'intonation la concernent), ce qui va dans le sens d'un éloignement à l'égard de l'épique traditionnel: cette impression est renforcée par l'étude de la place accordée à Blanchefleur, surreprésentée par rapport à son importance réelle. Le texte offre de fait une véritable «aventure de Blanchefleur » : des laisses 69 à 89 , 16 vers d'intonation sur 21 la citent, en adoptant qui plus est à deux reprises une structure de laisses parallèles, tout d'abord lors de son départ (laisse $72,73,74$ ), puis lorsqu'elle attend de voir celle qu'elle croit encore être sa fille (laisses 83 et 84). Pépin quant à lui n'est pas représenté en guerrier (sauf à la rigueur lorsqu'il tue le lion laisse 3), mais presque toujours dans sa fonction royale (notamment de justice,

${ }^{40}$ À noter, le jeu avec la pratique de la laisse similaire, aux laisses 116 et 117 : le premier hémistiche du vers d'intonation y est exactement le même, la rime y est presque la même, d'abord masculine puis féminine, mais au lieu d'être similaire à la première, la deuxième laisse présente simplement la poursuite logique du discours de Symon.

${ }^{41}$ Les guillemets successifs désignent l'emploi de termes anachroniques, faute de mieux. 
puisqu'il ouvre presque toutes les laisses au moment du dévoilement et du châtiment des traîtres, 1. 90 à 97), excepté lorsqu'il retrouve Berte : dans l'épisode, les laisses, s'ouvrant tantôt sur Berte tantôt sur Pépin, associent cette fois l'image du roi (les vers d'intonations, laisses 107 à 125 , comportent soit «sire» soit «li rois Pepins ») à celle d'un amant. Mais en réalité, si l'on part du principe qu'Adenet a effectivement voulu écrire une chanson de geste, ces choix permettent de mieux saisir l'idée qu'il se fait du genre. L'élément guerrier ne serait peut-être pas indispensable ${ }^{42}$, mais demeure essentiel le «personnel épique». Les figures royales (les mots «roi» et «reïne» sont très utilisés à l'intonation) sont associées à ce qui les distingue: la noblesse de leur caractère (rappelons la fréquence des épithètes), leur constance, leur piété, leur autorité; si les ancêtres de Charlemagne méritent une chanson de geste, c'est qu'ils annoncent naturellement leur descendant - ainsi Blanchefleur, comme Charlemagne, est alertée (certes a posteriori) des malheurs de son enfant. À cet égard, les derniers vers de "l'estoire», ceux sur lesquels se clôt l'œuvre, ressemblent à un clin d'œil, tant ils annoncent avec force la « véritable» chanson de geste liée à Charlemagne - le lexique épique et guerrier y sature (enfin!) littéralement les vers :

Aprés ot Charlemaine a la chiere hardie,

Qui puis fist seur paiens mainte grant envaïe.

Par lui fu la loys Dieu levee et essaucie,

Par lui fu mainte terre de paiens essillie,

Maint hiaume decoupé, mainte targe percie,

Maint hauberc derrompu, mainte teste trenchie ;

Molt guerroia de cuer sor la gent paiennie,

Si k'encore s'en duelent cil de cele lignie. (v. 3479-3486)

Comme dans toute chanson de geste, il s'agit donc de chanter les aventures exceptionnelles de héros qui se distinguent par la supériorité de leurs qualités et glorifient ainsi la royauté française. Cette interprétation d'«épicité» selon Adenet ne doit pourtant pas faire oublier l'originalité de l'angle choisi ; les rôles principaux sont sans conteste féminins (outre Berte et sa mère Blanchefleur, la bonne Constance qui recueille Berte, mais aussi les traitresses Aliste et Margiste), et les femmes de l'histoire conservent bien tous les traits de la féminité : à cet égard, il faudrait peut-être opposer Berte à Florence de Rome, plus prompte à jurer «par [s]on chief» et à insulter son bourreau - ce qui confirme la tonalité plus «épique » de Florence ${ }^{43}$.

L'étude des actions mises en valeur en tête de laisse confirme l'impression laissée par le choix des personnages. Nous avons vu que la chanson de geste privilégiait les «ralentissements» de la narration (reprise et parallélisme, représentations) et qu'en ce sens Berte s'inscrivait correctement dans le genre. Cependant la lecture confirme la distance néanmoins prise. D'une part, il est évident

${ }^{42}$ Dans une chanson peut-être destinée à Marie de France - rappelons néanmoins que les Enfances Ogier, récit guerrier à héros masculin, lui sont explicitement adressées.

${ }^{43}$ C'est ce qui, pour nous, justifie la résistance de Florence, critiquée par R. Colliot (op. cit., tome un, p. 119-120). À l'inverse, Berte ressemble aux hérö̈nes des récits folkloriques («l'innocente persécutée »), beaucoup moins actives. 
qu'ouvrir (exactement) la moitié des laisses sur Berte ou sur Blanchefleur ne favorise pas l'action épique. Si l'évocation du combat et ce qui l'entoure est naturellement hors de question, les actions en général ont peu l'honneur de l'intonation: on y part (cela au moins est traditionnel dans la chanson de geste), on y réagit (par des sentiments), à la rigueur on y parle, mais surtout on $\mathrm{y}$ 《est», beaucoup (c'est-à-dire on est dans un état d'esprit ou dans un lieu). Or la véritable stase n'est qu'une des possibilités du ralentissement épique, mais une rapide comparaison de Berte et de la Chanson de Roland donne l'impression que le verbe être est beaucoup plus présent à l'initiale dans l'œuvre d'Adenet (par exemple laisses 108, 109, 110,111,112, avec toutes les variations possibles: temporelle, géographique, psychologique, climatique...). Finalement cet «excès de ralentissement» suscite le doute: Adenet «en fait-il trop» dans le respect des caractéristiques du genre, ou adopte-t-il un style lié à son sujet et à son écriture, plus psychologique, voire poétique (?) que dans les chansons de geste traditionnelles? Ainsi Berte as grans piés respecte à la fois les formes et les fonctions du vers d'intonation épique, presque trop bien pourrait-on dire, alors même que la matière du récit témoigne d'autres orientations.

Faut-il en conclure, comme cela a d'ailleurs souvent été le cas, qu'Adenet est un bon technicien, mais qu'il n'a pas véritablement l'esprit épique, tel qu'on le conçoit généralement? Deux dernières caractéristiques de Berte devraient nous aider à mieux cerner son « ethos ».

D'une part, l'écho entre les vers d'intonation et l'intérieur des laisses. Nous avons vu que si n'importe quel type de vers ne peut se trouver à l'initiale ${ }^{44}$, en revanche les tournures qui servent aux vers d'intonation peuvent également se trouver à l'intérieur des laisses. Chez Adenet, il semble que ce soit plus fréquent que dans d'autres chansons. Certes, les structures de l'inversion, de la désignation longue de personnages, de l'apostrophe de début de discours se trouvent aussi très souvent placées en tête de vers dans le corps des laisses d'autres chansons - c'est le cas aussi dans Roland, par exemple. Il semble néanmoins que le recours à «Quant» en début de vers, notamment, soit plus étendu chez Adenet, qui l'affectionne dans les vers de conclusion (ce qui peut également se trouver dans d'autres chansons, nettement moins souvent cependant), mais aussi tout au long d'une laisse - citons par exemple les laisses 108 et 110 (quatre occurrences), 90 (trois occurrences), 123 et 138 (deux occurrences). Un relevé rapide dans des chansons aussi diverses que la Chanson de Roland et Gaydon témoigne d'un recours beaucoup plus rare à cette construction dans la laisse. D. Boutet la remarque dans les laisses très longues de Jehan de Lanson, en l'identifiant bien comme type de vers d'intonation ${ }^{45}-$ or ici, il ne s'agit jamais de laisses longues qui justifieraient le recours à ces relances, encore moins à plusieurs reprises dans la même laisse.

Les effets d'échos entre vers ou partie de vers à l'intérieur des laisses ${ }^{46}$ et vers d'intonation sont aussi assez fréquents; citons par exemple le vers 789 , dans la laisse 30 , et le vers d'intonation de la laisse suivante :

${ }^{44}$ Non pas du fait d'un arbitraire de la tradition: toutes les structures de phrases, tous les adverbes ne se prêtent pas aux exigences de l'intonation.

${ }^{45}$ D. Boutet, op. cit., p. 52.

${ }^{46}$ Non comme dans les enchainements traditionnels de chanson de geste, où c'est un vers issu de la fin de la laisse précédente qui se trouve repris en écho. Ici, il s'agit de vers pris au cœur 
Souz un arbre est assise, molt oi poi de delis. (1. 30)

La dame fu ou bois desouz un arbre assise. (1. 31)

Même remarque pour le vers 1506 dans la laisse 60, et le vers d'intonation de la laisse 61 :

Dolans en fu rois Floires, ce fu raisons et drois. (1. 60)

Dolans fy li rois Floires, car molt forment li poise. (1. 61)

Il faudrait un relevé rigoureux comparant d'autres chansons du XIII ${ }^{\mathrm{e}}$ siècle à Berte, mais un comptage de tous les vers internes identiques aux vers d'intonation montrerait sans doute un taux plus important chez Adenet; ce qui tendrait à confirmer qu'en ce qui concerne la forme des vers ${ }^{47}$, Adenet adapte son style au plus près des structures senties comme les plus épiques - à nouveau presque trop.

D'autre part, on peut relever dans le texte le retour d'un type de vers d'intonation qui semble spécifique à Adenet, du moins dans ces proportions. À quatorze reprises ${ }^{48}$, Adenet insère dans le vers d'intonation une prise de parole personnelle et une référence méta-textuelle évoquant l'écriture, la narration ou la lecture de l'œuvre. Si nous laissons de côté les deux cas de transition « classique », bien que peu usitée et mal perçue (laisses 59 et 106, « Ci lairons... »), et la nouvelle ouverture de la laisse 36 («Seignor, or escoutez...») également bien attestée, restent onze cas où Adenet éprouve le besoin, généralement dans le deuxième hémistiche $\mathrm{du}$ vers d'intonation, de faire allusion à la transmission du récit, à neuf reprises ${ }^{49} \mathrm{de}$ la même manière, en ouvrant le vers par une indication spatiale ou temporelle, et en le terminant par une prise de parole :

Aprés la mi aoust, ne quier que vous en mente... (1. 10)

Un mardi par matin, ce tesmoigne l'estoire..

Tout droit a Saint Quentin, c'est verités prouvée... (1. 142)

Li premiers des enfans, de ce ne doutez mie... (1. 144)

\footnotetext{
de la laisse.

${ }^{47}$ Rappelons que c'est beaucoup moins le cas pour les laisses.

${ }^{48}$ Nous n'avons pas intégré à cette liste l'ouverture du prologue, où le narrateur ne prend la parole qu'au vers 4 . Néanmoins la structure de cette «longue intonation » rejoint celle que nous évoquons ensuite.

${ }^{49}$ Laisses 2, 5, 10, 47, 65, 108, 129, 133, 144. Les deux derniers cas, laisses 68 et 131, placent la prise de parole en tête de vers : «Bien avez oÿ dire mainte fois et retraire »; «Bien avez entendu ainsi com adouba ». La première introduit une vérité générale (cf. par exemple dans Gaydon, laisse 187 - Gaydon, chanson de geste du XIII siècle, éd. J. Subrenat, LouvainParis, Peeters, 2007), la seconde reprend le contenu d'une laisse précédente.
} 
Le contenu de ces incises, on le voit, ne présente pas grand intérêt : il s'agit toujours d'une cheville qui atteste de la véracité du propos - parfois au sujet d'indications mineures. Mais ce type de vers ne se trouve pas habituellement à l'intonation (aucune trace dans Gaydon, par exemple) dans les chansons en décasyllabes, sauf lorsque l'auteur, qu'il écrive en décasyllabes ou en alexandrins, peine à terminer son vers (plus souvent d'ailleurs à l'intérieur des laisses) : on les trouve fréquemment dans les deux remaniements d'Ogier - pour lesquels les comparaisons de manuscrits montrent bien qu'il s'agit là d'échantillons d'un stock de formules de rembourrage, à peu près interchangeables ${ }^{50}$. Reste cependant qu'Adenet, dans le stock disponible, privilégie résolument celles qui correspondent le mieux au projet épique (mener un récit historiquement attesté), et réaffirment à l'intonation les conditions orales de transmission du texte, tout en lui donnant à nouveau l'occasion de se manifester dans son texte ${ }^{51}$ : lorsqu'il a recours au rembourrage, au moins est-ce conformément à l'esprit épique et à son goût propre - au demeurant, un recours si fréquent pour un auteur si scrupuleux indique peut-être que ce type de formule ne heurte pas son sens du style.

Ainsi, même lorsque l'on décèle quelques éléments originaux dans le traitement du vers d'intonation chez Adenet, il s'agit soit d'une dissémination du modèle à l'intérieur du vers, soit d'une facilité en partie compensée par la sélection d'un contenu caractéristique du genre. Pourtant, il est aussi perçu comme un auteur particulièrement engagé et sensible (A. Henry, R. Colliot) ${ }^{52}$, qui «conte avec vivacité et fraîcheur $»^{53}$ lorsqu'il prend la parole dans son récit « romanesque »faut-il décidément revenir à deux visages opposés d'Adenet?

Ce serait naturellement céder à la manie du classement : de fait, on imagine mal qu'un auteur persistât à respecter presque hyperboliquement les contraintes formelles d'un genre duquel il chercherait par ailleurs constamment à s'échapper par les thèmes abordés. Adenet le Roi, qui occupe des fonctions officielles auprès du duc de Brabant, puis du comte de Flandres, qui fut distingué par la reine Marie et le roi Édouard $\mathrm{I}^{\mathrm{er}}$, peut vraisemblablement être perçu comme un témoin du prestige associé au genre épique au XIII ${ }^{\mathrm{e}}$ siècle ${ }^{54}$, genre «noble» avant même que les genres ne soient classés : c'est le genre qui convient à la mise en valeur des héros (des héroïnes) historiques de la noblesse ${ }^{55}$ et c'est le genre qui, du fait de ses contraintes, exige la plus grande maîtrise technique, gageure qui n'était pas pour déplaire au chef

\footnotetext{
${ }^{50}$ À ce sujet, voir notre ouvrage La Tradition littéraire d'Ogier le Danois après le XIII ${ }^{e}$ siècle, permanence et renouvellement du genre épique médiéval, Paris, Champion, 2005, p. 126-127. Les auteurs de la continuation du début du XIV siècle et du remaniement du milieu du siècle utilisent également des chevilles encore plus creuses, du type «si com nous vous dison » ou «dont je (vous) fais mencion».

${ }^{51}$ La critique s'accorde sur la présence marquée d'Adenet dans ses œuvres - voir par exemple J. Horrent, «Charlemagne en France », Charlemagne et l'épopée romane, p. 28-31.

${ }_{52}$ A. Henry, op. cit., p. 47 ; R. Colliot, op. cit., p. 311-318.

${ }_{53}$ J. Horrent, art. cit., p. 30.

${ }^{54} \mathrm{Ou}$ de l'attrait qu'il continue à exercer, preuve que le genre n'a pas encore épuisé ses ressources.

${ }^{55}$ Les mises en prose des chansons de geste useront des cadres de la chronique.
} 
des ménestrels d'une cour comtale. Adenet insiste en effet à plusieurs reprises sur son métier: il évoque son apprentissage ${ }^{56}$, et nous savons qu'il se vante dans le prologue de Berte de l'originalité de ses «rimes»; choisir la forme épique, au XIII ${ }^{\mathrm{e}}$ siècle, c'est montrer son savoir-faire et ses connaissances, affirmer un goût pour une virtuosité formelle que le développement de la prose tend sans doute à faire se raréfier (on peut également se demander si la forte musicalité de la forme épique ne correspondait pas mieux aux conditions de transmission des récits dans une cour raffinée). Homme de métier également et non tenant d'un savoir archaïque ${ }^{57}$, Adenet le Roi écrit la chanson de geste comme le font les autres auteurs de son siècle, en y apportant en général les mêmes modifications et en y faisant se refléter les mêmes tendances - nous avons souvent été amenés à rapprocher notre texte de chansons contemporaines. Notons pourtant que son métier s'y montre parfois (pas toujours) plus ferme, puisque les conclusions que tire D. Boutet de l'étude des vers d'intonation de Jehan de Lanson - «le trouvère s'est davantage attaché à l'apparence formelle des vers d'intonation qu'à leur fonction épique » - devraient être nuancées à l'égard d'Adenet, chez qui le vers d'intonation s'inscrit plus souvent dans le ralentissement épique que dans la poursuite de la narration.

Berte as grans piés n'autorise donc pas plus que les Enfances Ogier que 1'on dissocie son respect, parfois trop marqué, d'une forme de son intérêt pour la psychologie et la morale. Attaché à un cadre qui lui permet de se mettre en valeur et qui convient à la noblesse de son sujet, Adenet, comme tous les auteurs qui ne sont pas des épigones, le renouvelle en y injectant d'autres éléments, en explorant d'autres champs : tantôt histoires de femmes (de reines) avec Berte, tantôt mentalité courtoise, esprit chevaleresque, avec Ogier. Or le fait que Berte et Ogier empruntent des chemins différents est particulièrement intéressant : s'il s'agissait vraiment d'une sorte de «surgissement incontrôlé» de l'esprit romanesque d'Adenet (alors qu'il s'est fixé pour tâche d'écrire une chanson de geste), les deux œuvres présenteraient sans doute plus d'unité dans le contenu. Il était facile d'intégrer plus de morale courtoise à Berte - ce qu'Adenet n'a pas fait. De la même manière qu'il s'amusera ensuite à la fantaisie avec Cleomadés, notre auteur expérimente ici la souplesse du genre épique, dans la forme unique duquel il fait entrer les thèmes qui, simplement, plaisent à son époque. La démarche n'a rien d'original, nous avons souvent pu la déceler chez d'autres auteurs, mais elle n'a rien non plus de maladroit. Une fois encore, il s'agit néanmoins de ne pas voir l'échec là où il n'y a que la liberté : Adenet n'est pas un mauvais auteur de chanson de geste, un romancier longtemps refoulé, c'est un auteur de chanson de geste de son temps.

Emmanuelle Poulain-Gautret Université d'Artois - Arras

\footnotetext{
${ }^{56}$ «Menestreus au bon duc Henri / Fui, cil m'aleva et norri / Et me fist mon mestier apprendre » (Cleomadés, v. 18589-18591). Constatant le savoir-faire d'Adenet, R. Colliot s'interroge sur l'existence en Brabant d'une «bonne école de formation pour les jongleurs » (op. cit., p. 274).

${ }^{57}$ A. Henry le voit comme « un provincial quelque peu attardé » (op. cit., p. 28).
} 